\title{
Closed-shell polycyclic aromatic hydrocarbon cations: a new category of interstellar polycyclic aromatic hydrocarbons
}

\author{
Douglas M. Hudgins, Charles W. Bauschlicher, Jr*, Louis J. Allamandola \\ NASA Ames Research Center, MS 230-3, Moffett Field, CA 94035, USA
}

Received 11 July 2000; received in revised form 14 September 2000; accepted 18 September 2000

\begin{abstract}
Density functional theory has been employed to calculate the harmonic frequencies and intensities of a range of polycyclic aromatic hydrocarbon (PAH) cations that explore both size and electronic structure effects on the infrared spectroscopic properties of these species. The sample extends the size range of PAH species considered to more than 50 carbon atoms and includes several representatives from each of two heretofore unexplored categories of PAH cations: (1) fully benzenoid PAH cations whose carbon skeleton is composed of an odd number of carbon atoms $\left(\mathrm{C}_{\text {odd }} \mathrm{PAHs}\right)$; and (2) protonated PAH cations $\left(\mathrm{HPAH}^{+}\right)$. Unlike the radical electronic structures of the PAH cations that have been the subject of previous theoretical and experimental work, the species in these two classes have a 'closed'-shell electronic configuration. The calculated spectra of circumcoronene, $\mathrm{C}_{54} \mathrm{H}_{18}$, in both neutral and (radical) cationic form are also reported and compared with those of the other species. Overall, the $\mathrm{C}_{\text {odd }}$ PAHs spectra are dominated by strong CC stretching modes near $1600 \mathrm{~cm}^{-1}$ and display spectra that are remarkably insensitive to molecular size. The $\mathrm{HPAH}^{+}$species evince a more complex spectrum consistent with the added contributions of aliphatic modes and their generally lower symmetry. Finally, for both classes of closed-shell cations, the intensity of the aromatic $\mathrm{CH}$ stretching modes is found to increase with molecular size far out of proportion with the number of $\mathrm{CH}$ groups, approaching a value more typical of neutral PAHs for the largest species studied. (C) 2001 Published by Elsevier Science B.V.
\end{abstract}

Keywords: Infrared spectroscopy; Polycyclic aromatic hydrocarbon; Harmonic frequencies and intensities; Interstellar molecules

\section{Introduction}

The discovery of an unexpected infrared emission feature from two planetary nebulae by Gillett, Forrest, and Merrill in 1973 marked the

\footnotetext{
* Corresponding author. Tel.: + 1-650-6046231; Fax: + 1650-6045244.

E-mail address: bauschli@pegasus.arc.nasa.gov (C.W. Bauschlicher, Jr).
}

beginning of an exciting chapter of modern astrophysics [1]. Gillett et al. recognized that this band near $885 \mathrm{~cm}^{-1}(11.3 \mu \mathrm{m})$ was associated with interstellar dust, and that its identification could give important insight into dust formation and evolution through the latter stages of the stellar life cycle. Moreover, this feature could not be associated with graphite grains, long thought to be produced in intense circumstellar outflows 
from late-type, carbon-rich stars. Subsequent pioneering observations showed this was just one part of a now well-known spectrum of features emitted from a wide variety of very different astronomical objects (for example, see Refs. [25]). This spectrum is characterized by dominant features near 3030, 1610, 1280, 1150, and 890 $\mathrm{cm}^{-1}(3.3,6.2,7.7,8.6$, and $11.2 \mu \mathrm{m})$ as well as a number of minor bands and underlying continua. The brightest emission is observed from dusty regions exposed to intense ultraviolet radiation. Surprisingly, the age and history of the material seem to be relatively unimportant. Similar emission spectra are observed from objects that span the lifecycle of matter in the interstellar medium (ISM) - from objects only a few thousand years in age (late carbon star ejecta and planetary nebulae shells) to those millions of years in age (H II regions, reflection nebulae, and the diffuse ISM) [6-11]. Understanding the source of this unexpected, yet widespread, phenomenon has become an important problem in astrophysics.

The idea now gaining acceptance, that stochastically heated, gas-phase, polycyclic aromatic hydrocarbons (PAHs) are the band carriers, was first put forth over a decade ago $[12,13]$. This attribution is based on several pieces of 'circumstantial' evidence that point to these species. First, the interstellar emission is non-thermal in nature. The banded (rather than continuous) nature of the spectrum, the typically large feature/continuum ratio, and the close association with ultraviolet radiation all indicate that the emission is due to infrared fluorescence from gas-phase molecules excited by the absorption of single ultraviolet and visible photons rather than thermal emission from a solid material [14]. Second, careful observations of planetary nebulae have established that the fraction of the total infrared energy that is emitted through these features is closely correlated with the amount of available carbon [15], indicating that the gas-phase molecular carriers are carbon rich. Third, since the carbon-rich carriers must survive under remarkably harsh conditions, they must also be extremely stable. Finally, although there are variations among the relative band intensities, the features are correlated $[16,17]$, implying that a single class of chemical species is responsible. Of course, any proposed carrier must have an IR spectrum consistent with the positions and intensities of these bands. As a molecular class, PAHs readily accommodate all these constraints.

Originally, the principal reason for the assignment to PAHs was the suggestive, but far from perfect, resemblance of the interstellar 'emission' spectra to the then-available infrared 'absorption' spectra, primarily those of PAH clusters dispersed in $\mathrm{KBr}$ pellets or soot particles. Unfortunately, although rich, this spectral database was not adequate to squarely address the astronomical questions since such laboratory conditions strongly perturb the spectrum and are far from those in the interstellar emission zones. Moreover, if PAHs are indeed present in the highly energetic emission zones, they are likely to be ionized [13] and, until recently, there was no spectroscopic data available on the infrared properties of PAH ions. Thus, the spectral database initially available was not sufficient for a critical test of the PAH hypothesis nor, if the hypothesis held up to close scrutiny, was it up to the task of exploiting PAHs as probes of the emission zones. To truly test the PAH hypothesis, special techniques for studying individual PAHs and PAH ions under astrophysically relevant conditions were required.

Motivated in no small part by their emerging interstellar importance, the past decade has seen a renaissance in experimental and theoretical methods aimed at determining the physical [18-20], chemical [21-25], and spectroscopic [26-38] impact of PAHs in the interstellar medium. Particularly relevant to the problem of the interstellar infrared emission, these efforts have produced a large and growing database of the infrared spectroscopic properties of PAHs and PAH ions that are directly relevant to the astrophysical problem [39-55]. These studies have included PAHs in neutral, cationic and anionic forms, and encompass species ranging in size from ten to 32 carbon atoms. Nevertheless, to date, both experimental and theoretical studies in this area have focused primarily on the determination of the spectroscopic properties of the sorts of conventional structures that characterize terrestrially stable, commercially available PAHs. Such PAHs in their 
neutral forms (indeed, virtually all stable chemical compounds) have a 'closed-shell' electronic structure - one having only paired electrons. This necessarily implies that their daughter cations all have the alternative 'free-radical' or 'open-shell' electronic structure carrying one unpaired electron. Regardless of their ionization state, due to their incomplete electronic structure, open-shell species are inherently less stable and more reactive than their closed-shell counterparts. Despite the focus on $\mathrm{PAH}$ radical cations, $\mathrm{PAH}$ cations that have a closed-shell configuration are not unknown. Two classes of these are of particular interest to astrophysics: (1) fully benzenoid PAH cations with an odd number of carbon atoms $\left(\mathrm{C}_{\text {odd }} \mathrm{PAH}\right.$ cations $)$; and (2) protonated PAHs $\left(\mathrm{HPAH}^{+}\right)$. Representative structures from each of these classes are shown

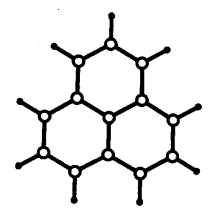

$\mathrm{C}_{13} \mathrm{H}_{9}$

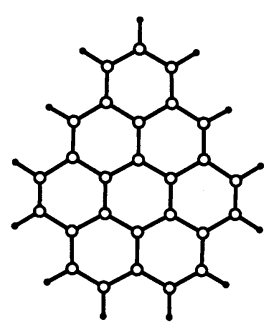

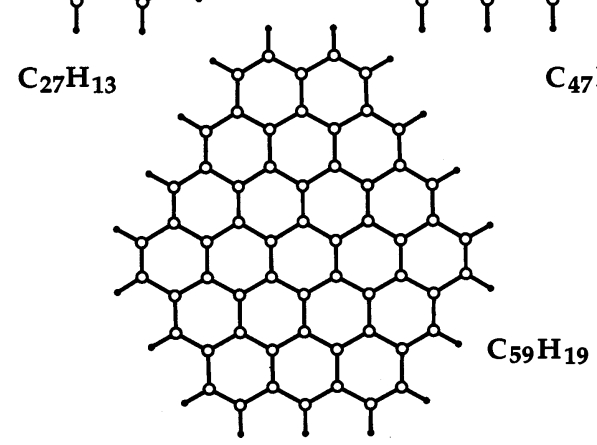

Fig. 1. The structures of the $\mathrm{C}_{\text {odd }} \mathrm{PAH}$ cations considered in this work. The species all have a fully benzenoid skeleton composed of an odd number of carbon atoms. The open circles represent carbon atoms.

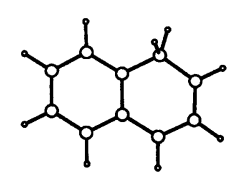

1-hydro-naphthalene

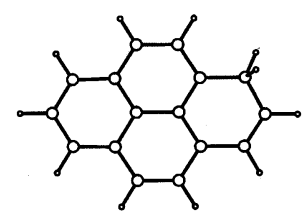

1-hydro-pyrene

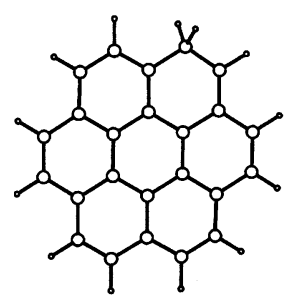

1-hydro-coronene

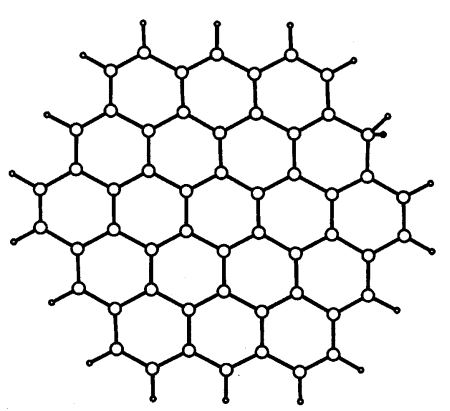

3-hydro-circumcoronene
Fig. 2. The structures of the protonated PAH cations, $\mathrm{HPAH}^{+}$, considered in this work. Note the aliphatic $-\mathrm{CH}_{2}-$ groups that replace one aromatic $\mathrm{CH}$ in each case. Large circles, carbon atoms; small circles, hydrogen atoms.

in Figs. 1 and 2, respectively. For such closed-shell cations, it is the corresponding neutral species that have the highly reactive radical electron configuration and are not isolatable. The lack of a suitable precursor presents serious practical difficulties that have yet to be overcome with the current experimental techniques. Thus, these classes of closedshell PAH cations make excellent subjects for a theoretical investigation of their infrared spectroscopic properties.

An additional noteworthy aspect of the computational results presented in the following is the molecular size range of the PAH species that are considered. To date, most studies (experimental and theoretical alike) have focused on PAH molecules containing only up to about 30 carbon atoms. In the theoretical studies, this limitation was imposed largely by the significant amounts of CPU time required for calculations of larger species. However, the latest experimental and theoretical studies suggest that, while molecules containing as few as 20-30 carbon atoms may contribute to the interstellar infrared emission 
spectrum, the strongest interstellar emission features in the $1600-1100 \mathrm{~cm}^{-1}(6-9 \mu \mathrm{m})$ region are dominated by species comprised of 50-100 carbon atoms $[18,35,56]$. It is therefore important to the astrophysical problem that studies of PAH cations be extended to species of this size. In this manuscript, with the benefit of several key advances [57] in the calculation of analytic second derivatives (which have been implemented in the GAUSSIAN 98 package of programs), we report computed IR spectra of PAH cations as large as 59 carbon atoms.

This paper is laid out as follows. The computational methods are described in Section 2. In Section 3, the calculated harmonic frequencies and intensities for the two classes of closed-shell PAH cations are presented and discussed according to class, with the $\mathrm{C}_{\text {odd }}$ PAH cations considered in Section 3.1, and the protonated PAH cations considered in Section 3.2. Finally, the astrophysical implications of the results are considered in Section 4.

\section{Computational methods}

The geometries are optimized, and the harmonic frequencies and infrared intensities are computed using the B3LYP [58] hybrid [59] functional in conjunction with the $4-31 \mathrm{G}$ basis sets
[60]. Calibration calculations, which have been carried out for selected systems [36], show that a single scale factor of 0.958 brings the B3LYP harmonic frequencies computed using the 4-31G basis set into excellent agreement with the experimental fundamentals; for example, in naphthalene, the average absolute error is $4.4 \mathrm{~cm}^{-1}$ and the maximum error is $12.4 \mathrm{~cm}^{-1}$. To calibrate the intensities, we have performed B3LYP calculations on naphthalene, and the naphthalene and 1and 2-hydronaphthalene cations, as well as pyrene, and the pyrene and 1-, 2-, and 4-hydropyrene cations using the $6-31+\mathrm{G}^{*}$ and $6-31++$ $\mathrm{G}^{* *}$ basis sets. The computed ratios of the intensities obtained using these higher level basis sets to those obtained using the $4-31 \mathrm{G}$ basis set are presented in Table 1. Excluding the naphthalene cation in the $6-31++\mathrm{G}^{* *}$ basis set, improving the basis set generally reduces the aromatic $\mathrm{C}-\mathrm{H}$ stretching intensity. For the pyrene species considered, this reduction is found to be as large as two- to fourfold. While the impact of the higher level basis sets is more ambiguous for the naphthalene species, it should be noted that the absolute intensities of the aromatic $\mathrm{CH}$ stretching modes in these species are very small, tending to exaggerate the relative impact of any variations in the calculations. For example, in the naphthalene cation, the aromatic $\mathrm{C}-\mathrm{H}$ stretch intensity changes from $1.45 \mathrm{~km} / \mathrm{mol}$ in the $4-31 \mathrm{G}$ basis set

Table 1

The basis set dependence of the calculated total aromatic and aliphatic $\mathrm{CH}$ stretching intensities for the naphthalene and pyrene species considered in Section 3.2, compared with that of the remaining, non-CH stretching modes in those species

\begin{tabular}{|c|c|c|c|c|c|c|}
\hline \multirow[t]{3}{*}{ Species } & \multicolumn{3}{|c|}{$6-31+\mathrm{G}^{*} / 4-31 \mathrm{G}$} & \multicolumn{3}{|c|}{$6-31++\mathrm{G}^{* *} / 4-31 \mathrm{G}$} \\
\hline & \multicolumn{2}{|c|}{ CH stretching modes } & \multirow[t]{2}{*}{ All other modes } & \multicolumn{2}{|c|}{$\mathrm{CH}$ stretching modes } & \multirow[t]{2}{*}{ All other modes } \\
\hline & Aromatic & Aliphatic & & Aromatic & Aliphatic & \\
\hline $\mathrm{C}_{10} \mathrm{H}_{8}$ & 0.87 & & 0.83 & 0.71 & & 1.12 \\
\hline $\mathrm{C}_{10} \mathrm{H}_{8}^{+}$ & 0.83 & & 0.92 & 1.98 & & 0.95 \\
\hline $\mathrm{C}_{10} \mathrm{H}_{9}^{+\mathrm{a}}$ & 0.68 & 0.95 & 0.94 & 0.98 & 1.08 & 0.96 \\
\hline $\mathrm{C}_{16} \mathrm{H}_{10}$ & 0.86 & & 0.85 & 0.71 & & 1.06 \\
\hline $\mathrm{C}_{16} \mathrm{H}_{10}^{+}$ & 0.56 & & 0.92 & 0.27 & & 0.95 \\
\hline $\mathrm{C}_{16} \mathrm{H}_{11}^{+\mathrm{b}}$ & 0.61 & 0.93 & 0.94 & 0.39 & 1.13 & 0.97 \\
\hline
\end{tabular}

a Average for two possible hydronaphthalene cation structures.

${ }^{\mathrm{b}}$ Average for three possible hydropyrene cation structures. 
to $2.86 \mathrm{~km} / \mathrm{mol}$ for the $6-31++\mathrm{G}^{* *}$ basis set; so while the ratio is much larger than 1 , the absolute change is small. Thus, the calibration data provided by the pyrene system is expected to provide a more realistic assessment of the accuracy of the calculations for $\mathrm{PAH}$ species as a whole.

Interestingly, unlike the aromatic $\mathrm{C}-\mathrm{H}$ stretching intensity, the aliphatic $\mathrm{C}-\mathrm{H}$ stretching intensities and the total non-C-H stretching intensities are relatively independent of the basis set used. Thus this work, along with previous work [36,43], indicates that, while the $4-31 \mathrm{G}$ intensities of non$\mathrm{C}-\mathrm{H}$ stretching modes in PAHs are reasonably accurate, the aromatic $\mathrm{C}-\mathrm{H}$ stretching intensities are too large by some two- to threefold. The current work also shows that, unlike their aromatic counterparts, the accuracy of the computed aliphatic $\mathrm{C}-\mathrm{H}$ stretching intensities is comparable with that of the non-C-H stretching modes. Thus, the overestimation of the intensities with the 4$31 \mathrm{G}$ basis set appears to be limited specifically to the aromatic $\mathrm{C}-\mathrm{H}$ stretching modes. Therefore, since this effect is variable in magnitude and limited to only a single class of modes, we report the 4-31G intensities as computed for all bands with the stipulation that the aromatic $\mathrm{CH}$ stretching intensities probably represent an overestimate of their actual intensities. We should also note that, regardless of their composition, when two modes of the same symmetry are close in energy, their relative intensities are sensitive to the level of theory, but the sum of their intensities is very reliable.

The B3LYP calculations were performed using the GAUSSIAN 98 computer codes [61]. The complete harmonic frequencies and intensities, including those obtained with the higher level basis sets, can be found at 〈http://ccf.arc.nasa.gov/ cbauschl/closed-shell.data $\rangle$.

\section{Results}

The results of our theoretical analyses of closed-shell PAH cations are presented next, organized according to class, with the infrared spectra of the $\mathrm{C}_{\text {odd }} \mathrm{PAH}$ cations considered first, followed by that of the protonated PAH cations.

\subsection{Fully benzenoid PAH cations containing an odd number of carbon atoms ( $C_{\text {odd }} P A H$ cations)}

These closed-shell PAH cations are fully benzenoid (i.e. composed only of fused six-membered rings) species whose skeleton is composed of an odd number of carbon atoms. This investigation was motivated by the work of Weilmunster, Keller, and Homann [62], who have analyzed the PAH cation structures that are produced in combustion processes, the processes considered most likely involved in the production of interstellar PAHs [63,64]. Employing time-of-flight mass spectrometry to monitor the formation and growth of PAH cations in flames, Weilmunster et al. found that the PAH cations exhibit their own unique growth chemistry, involving species and structures that differ significantly from those found in the neutral PAH population. Not surprisingly, small PAH cations appear first, early in the combustion region, with sequentially larger species becoming important with increasing depths into the combustion region. What is surprising is the distribution of the structures in the flame PAH cation population. They report that, for cations up to about 50 carbon atoms, structures with an odd number of carbon atoms actually dominate the population. Furthermore, the authors determined that these odd carbon number species were not simply species that incorporated a five-membered ring in their structures but were, instead, fully benzenoid structures. Such structures are illustrated in Fig. 1, which shows the structures of the species considered in this work. As one approaches 50 carbon atoms, the populations of the species with even and odd numbers of carbon atoms converge and, above this size, appear in roughly equal proportions. Considering the energetic conditions in many of the infrared emission zones and the inherent stability of the closed-shell Codd PAH cations, if interstellar PAHs are indeed produced under combustion-like conditions in carbon-rich circumstellar shells, such species may well represent important members of the smaller PAH population in these regions.

The results of the aforementioned combustion experiments can be understood in terms of the 
electronic structures of the ions involved. Quite simply, $\mathrm{C}_{\text {even }} \mathrm{PAH}$ cations necessarily have an open-shell, radical structure, while the $\mathrm{C}_{\text {odd }}$ PAHs have the chemically more favorable closed-shell structure and are therefore preferred. Presumably, by the time one reaches 50 carbon atoms, stability provided by electron delocalization over the extensive aromatic framework dilutes the energetic cost associated with maintaining the odd electron to the point that there is no longer any significant preference for closed-shell over open-shell structures.

Synthetic representations of the theoretically calculated infrared spectra of several $\mathrm{C}_{\text {odd }} \mathrm{PAH}$ cations ranging from $\mathrm{C}_{13} \mathrm{H}_{9}^{+}$to $\mathrm{C}_{59} \mathrm{H}_{19}^{+}$are presented in Fig. 3. These simulations were generated by assigning each calculated band a $20 \mathrm{~cm}^{-1}$ full-width at half-height (FWHH) gaussian profile of the appropriate intensity. Such a profile is consistent with that expected from molecules emitting under the conditions of the interstellar problem [26]. Abbreviated tabulations of the calculated band positions, symmetries, and intensities can be found in Tables 2 and 3. In those tables, the data at frequencies below $2000 \mathrm{~cm}^{-1}$ have been truncated at the $10 \%$ level. The infrared active modes in the $3200-2800 \mathrm{~cm}^{-1} \mathrm{CH}$ stretching region are presented in their entirety, in accordance with their more diminutive nature and their role in the following discussion. Complete tabulations of the calculated data (including both IR active and inactive modes) have been posted on the Internet at 〈http://ccf.arc.nasa.gov/ cbauschl/closed-shell.data $\rangle$. Inspection of these data reveals that each of the spectra are dominated by three strong features in the 1600-1100 $\mathrm{cm}^{-1}(6.25-9.1 \mu \mathrm{m})$ region, which is characteristic of aromatic $\mathrm{CC}$ stretching and $\mathrm{CH}$ in-plane wagging vibrations. In some cases, these features represent a single very strong band, while in others they reflect an overlapping of two or more features that fall close to each other (see Tables 2 and 3). The band near $1600 \mathrm{~cm}^{-1}$ (a strong doublet in the spectrum of $\mathrm{C}_{13} \mathrm{H}_{9}^{+}$) is consistently the strongest of these. The other two typically fall in the mid-1300 $\mathrm{cm}^{-1}(7.5 \mu \mathrm{m})$ and the low 1200 $\mathrm{cm}^{-1}(8.3 \mu \mathrm{m})$ regions. While it is well established that the strongest infrared bands of PAH cations tend to fall in the $1600-1100 \mathrm{~cm}^{-1}$ region, it is unusual to find the band near $1600 \mathrm{~cm}^{-1}$ to be the strongest in the spectrum (see, for example, Figs. 6-9). It is also unusual to see such a similarity in the pattern of these strong bands over such a large range of molecular sizes. Indeed, comparison of the spectra in Fig. 3 with the data currently available in the literature [39-55] shows that, throughout the infrared, the spectral variations of $\mathrm{C}_{\text {odd }}$ PAHs over a wide range of molecular sizes are more subtle than those of neutral PAHs and PAH radical cations. They are also more subtle than those found for the closed-shell protonated PAH cations that are discussed in Section 3.2 (for reference, compare also the spectra of the naphthalene radical cation and the circumcoronene radical cation in Fig. 6a and Fig. 9b, respectively). At this stage, it is unclear whether this is a characteristic of the particular series of molecules studied, or whether this is a general feature of this class of PAH cation. Another interesting aspect of this region of the spectrum is the size dependence of the dominant band positions. Specifically, highest frequency features in this region all tend to cluster between 1595 and $1575 \mathrm{~cm}^{-1}$, and show little dependence on molecular size. The positions of the other two dominant bands, on the other hand, shift steadily toward lower frequencies with increasing molecular size from 1361 and 1259 $\mathrm{cm}^{-1}$ (7.4 and $\left.7.94 \mu \mathrm{m}\right)$ in the $\mathrm{C}_{13} \mathrm{H}_{9}^{+}$cation to 1318 and $1189 \mathrm{~cm}^{-1}$ (7.6 and $\left.8.4 \mu \mathrm{m}\right)$ in the $\mathrm{C}_{59} \mathrm{H}_{19}^{+}$cation. This behavior stands in marked contrast to that of PAH radical cations [56] where it is the bands near $1600 \mathrm{~cm}^{-1}$ that shift to higher frequencies with increasing molecular size, while the bands near $1300 \mathrm{~cm}^{-1}$ remain more or less static. In both cases, however, the net effect is an increase in the spacing between these features.

A final noteworthy aspect of this series of spectra is the molecular size dependence of the aromatic $\mathrm{CH}$ stretching features in the 3100-3050 $\mathrm{cm}^{-1}(3.23-3.28 \mu \mathrm{m})$ range. First, inspection of the data in Tables 2 and 3 shows that the position of the dominant $\mathrm{CH}$ stretching feature undergoes a distinct red shift with increasing molecular size, decreasing from a maximum of $3106 \mathrm{~cm}^{-1}(3.22$ $\mu \mathrm{m})$ in the $\mathrm{C}_{13} \mathrm{H}_{9}^{+}$cation down to $3078 \mathrm{~cm}^{-1}$ $(3.25 \mu \mathrm{m})$ for the $\mathrm{C}_{59} \mathrm{H}_{19}^{+}$cation. At the same time, 


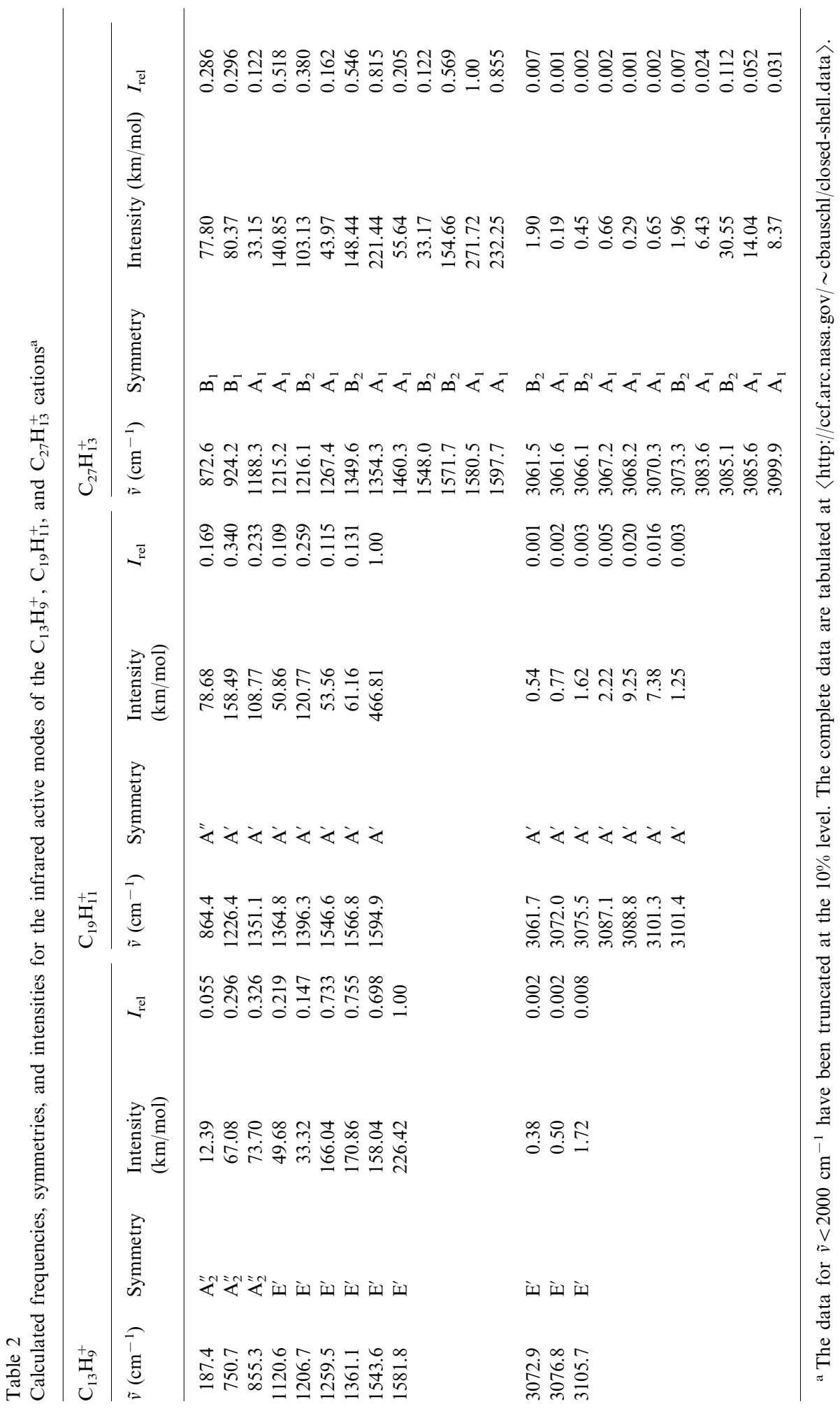



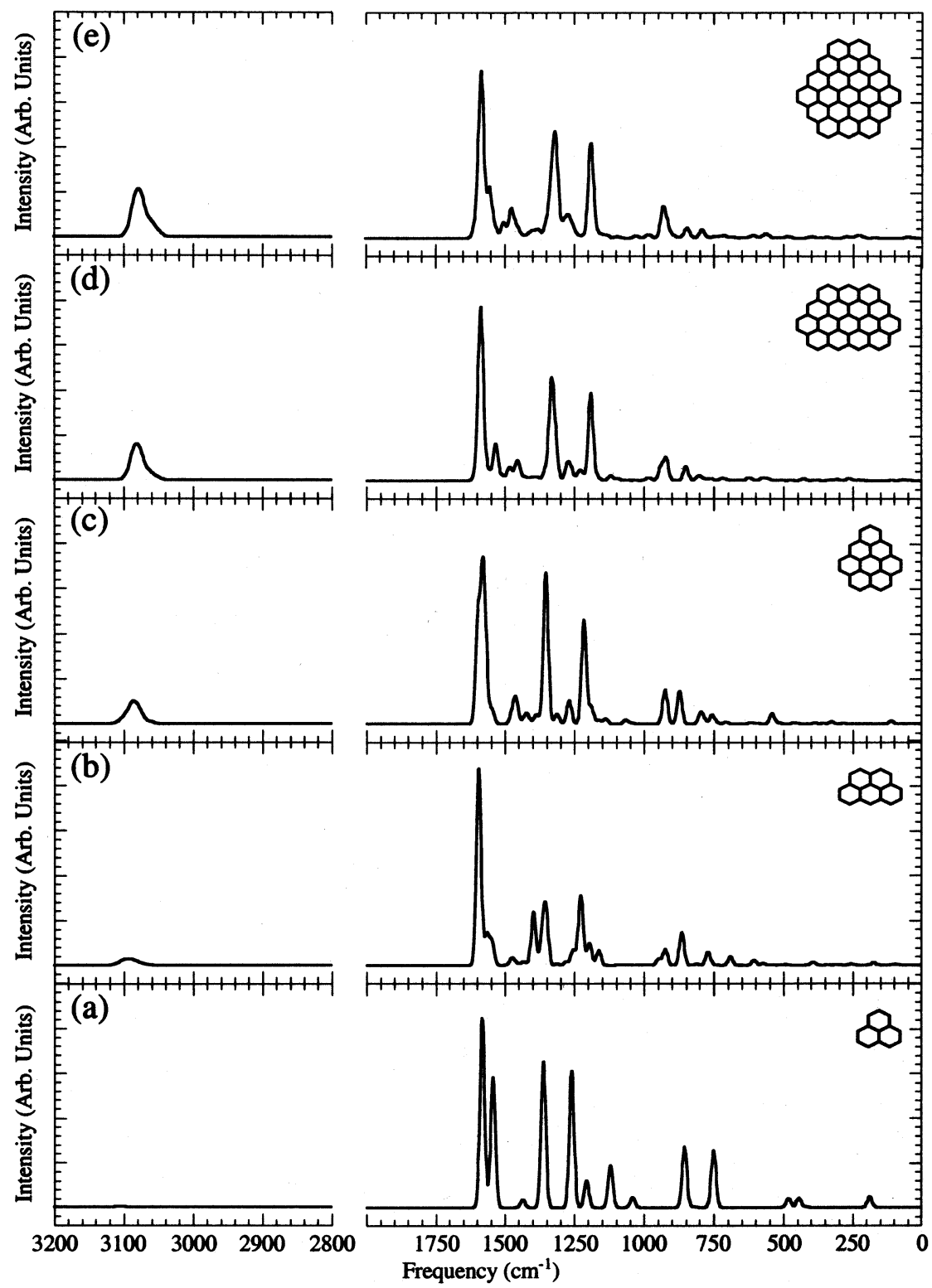

Fig. 3. Representations of the B3LYP computed IR spectra of (a) $\mathrm{C}_{13} \mathrm{H}_{9}^{+}$, (b) $\mathrm{C}_{19} \mathrm{H}_{11}^{+}$, (c) $\mathrm{C}_{27} \mathrm{H}_{13}^{+}$, (d) $\mathrm{C}_{47} \mathrm{H}_{17}^{+}$, and (e) $\mathrm{C}_{59} \mathrm{H}_{19}^{+}$. These simulations were generated by assigning each calculated band a $20 \mathrm{~cm}^{-1} \mathrm{FWHH}$ gaussian profile of the appropriate intensity.

the intrinsic intensity per $\mathrm{CH}$ group of these modes increases from $0.30 \mathrm{~km} / \mathrm{mol} \cdot \mathrm{CH}$ group for $\mathrm{C}_{13} \mathrm{H}_{9}^{+}(2.6 \mathrm{~km} / \mathrm{mol} \div 9 \mathrm{CH}$ groups $)$ to $15.3 \mathrm{~km} /$ mol. $\mathrm{CH}$ group for $\mathrm{C}_{59} \mathrm{H}_{19}^{+}(290 \mathrm{~km} / \mathrm{mol} \div 19 \mathrm{CH}$ groups). Note that, while the absolute intensities of these modes have not been corrected for the expected computational overestimate, the varia- tion that is reflected in these numbers should be independent of that correction (the same correction likely applies to all the numbers). Although some increase in the intensity of the $\mathrm{CH}$ stretching features is expected simply on the basis of the increasing number of aromatic $\mathrm{CH}$ groups in the molecule, the observed magnitude of this effect is 
Table 3

Calculated frequencies, symmetries, and intensities for the infrared active modes of the $\mathrm{C}_{47} \mathrm{H}_{17}^{+}$and $\mathrm{C}_{59} \mathrm{H}_{19}^{+}$cations ${ }^{\mathrm{a}}$

\begin{tabular}{|c|c|c|c|c|c|c|c|}
\hline \multicolumn{4}{|l|}{$\mathrm{C}_{47} \mathrm{H}_{17}^{+}$} & \multicolumn{4}{|l|}{$\mathrm{C}_{59} \mathrm{H}_{19}^{+}$} \\
\hline$\tilde{v}\left(\mathrm{~cm}^{-1}\right)$ & Symmetry & Intensity $(\mathrm{km} / \mathrm{mol})$ & $I_{\text {rel }}$ & $\tilde{v}\left(\mathrm{~cm}^{-1}\right)$ & Symmetry & Intensity $(\mathrm{km} / \mathrm{mol})$ & $I_{\text {rel }}$ \\
\hline 850.4 & $\mathrm{~B}_{1}$ & 61.64 & 0.108 & 792.2 & $\mathrm{~B}_{1}$ & 35.57 & 0.100 \\
\hline 920.4 & $\mathrm{~B}_{1}$ & 103.42 & 0.181 & 845.3 & $\mathrm{~B}_{1}$ & 41.92 & 0.118 \\
\hline 938.5 & $\mathrm{~B}_{1}$ & 64.00 & 0.112 & 919.0 & $\mathrm{~B}_{1}$ & 72.39 & 0.204 \\
\hline 1188.9 & $\mathrm{~B}_{2}$ & 143.36 & 0.250 & 932.7 & $\mathrm{~B}_{1}$ & 123.00 & 0.347 \\
\hline 1190.8 & $\mathrm{~A}_{1}$ & 142.30 & 0.249 & 1184.5 & $\mathrm{~A}_{1}$ & 183.27 & 0.517 \\
\hline 1192.1 & $\mathrm{~B}_{2}$ & 127.24 & 0.222 & 1189.9 & $\mathrm{~B}_{2}$ & 103.56 & 0.292 \\
\hline 1275.0 & $\mathrm{~A}_{1}$ & 60.17 & 0.105 & 1192.8 & $\mathrm{~B}_{2}$ & 91.41 & 0.258 \\
\hline 1317.5 & $\mathrm{~B}_{2}$ & 178.04 & 0.311 & 1193.7 & $A_{1}$ & 116.40 & 0.328 \\
\hline 1331.7 & $\mathrm{~A}_{1}$ & 173.37 & 0.303 & 1254.2 & $\mathrm{~A}_{1}$ & 46.58 & 0.131 \\
\hline 1331.9 & $\mathrm{~B}_{2}$ & 259.21 & 0.453 & 1270.1 & $\mathrm{~A}_{1}$ & 83.02 & 0.234 \\
\hline 1483.1 & $\mathrm{~A}_{1}$ & 59.42 & 0.104 & 1286.3 & $\mathrm{~A}_{1}$ & 50.94 & 0.144 \\
\hline 1532.7 & $\mathrm{~B}_{2}$ & 172.33 & 0.301 & 1306.4 & $\mathrm{~A}_{1}$ & 73.64 & 0.208 \\
\hline 1580.1 & $\mathrm{~A}_{1}$ & 235.10 & 0.411 & 1314.1 & $\mathrm{~B}_{2}$ & 297.25 & 0.838 \\
\hline 1583.4 & $\mathrm{~B}_{2}$ & 102.08 & 0.178 & 1323.5 & $\mathrm{~A}_{1}$ & 199.73 & 0.563 \\
\hline \multirow[t]{12}{*}{1589.3} & $\mathrm{~B}_{2}$ & 572.48 & 1.00 & 1331.0 & $\mathrm{~A}_{1}$ & 121.28 & 0.342 \\
\hline & & & & 1340.0 & $\mathrm{~B}_{2}$ & 52.95 & 0.149 \\
\hline & & & & 1351.0 & $\mathrm{~A}_{1}$ & 40.38 & 0.114 \\
\hline & & & & 1474.9 & $\mathrm{~B}_{2}$ & 72.74 & 0.205 \\
\hline & & & & 1477.1 & $\mathrm{~A}_{1}$ & 43.08 & 0.121 \\
\hline & & & & 1503.6 & $\mathrm{~B}_{2}$ & 64.38 & 0.181 \\
\hline & & & & 1553.9 & $A_{1}$ & 211.63 & 0.597 \\
\hline & & & & 1575.4 & $A_{1}$ & 113.48 & 0.320 \\
\hline & & & & 1581.3 & $\mathrm{~B}_{2}$ & 306.42 & 0.864 \\
\hline & & & & 1585.1 & $\mathrm{~A}_{1}$ & 354.75 & 1.00 \\
\hline & & & & 1592.6 & $A_{1}$ & 90.04 & 0.254 \\
\hline & & & & 1604.2 & $\mathrm{~B}_{2}$ & 47.38 & 0.134 \\
\hline 3057.3 & $\mathrm{~A}_{1}$ & 2.19 & 0.004 & 3055.3 & $\mathrm{~A}_{1}$ & 0.98 & 0.003 \\
\hline 3057.3 & $\mathrm{~B}_{2}$ & 5.73 & 0.010 & 3055.8 & $\mathrm{~A}_{1}$ & 3.02 & 0.009 \\
\hline 3059.7 & $A_{1}$ & 6.84 & 0.012 & 3057.1 & $\mathrm{~B}_{2}$ & 3.43 & 0.010 \\
\hline 3060.1 & $\mathrm{~A}_{1}$ & 5.34 & 0.009 & 3057.3 & $\mathrm{~A}_{1}$ & 11.06 & 0.031 \\
\hline 3061.6 & $\mathrm{~B}_{2}$ & 0.98 & 0.002 & 3058.2 & $\mathrm{~B}_{2}$ & 17.34 & 0.049 \\
\hline 3062.6 & $\mathrm{~A}_{1}$ & 6.67 & 0.012 & 3058.4 & $\mathrm{~A}_{1}$ & 0.23 & 0.001 \\
\hline 3063.0 & $\mathrm{~B}_{2}$ & 1.83 & 0.003 & 3059.5 & $\mathrm{~B}_{2}$ & 11.98 & 0.034 \\
\hline 3063.1 & $A_{1}$ & 0.93 & 0.002 & 3060.0 & $A_{1}$ & 4.71 & 0.013 \\
\hline 3079.5 & $\mathrm{~B}_{2}$ & 6.90 & 0.012 & 3060.7 & $\mathrm{~B}_{2}$ & 1.38 & 0.004 \\
\hline 3079.8 & $\mathrm{~A}_{1}$ & 20.76 & 0.036 & 3060.8 & $\mathrm{~A}_{1}$ & 1.37 & 0.004 \\
\hline 3080.0 & $\mathrm{~B}_{2}$ & 19.77 & 0.035 & 3062.9 & $\mathrm{~B}_{2}$ & 3.49 & 0.010 \\
\hline 3080.1 & $\mathrm{~A}_{1}$ & 34.34 & 0.060 & 3077.3 & $\mathrm{~B}_{2}$ & 6.04 & 0.017 \\
\hline 3082.1 & $\mathrm{~B}_{2}$ & 71.29 & 0.125 & 3077.6 & $\mathrm{~A}_{1}$ & 45.76 & 0.129 \\
\hline \multirow[t]{4}{*}{3082.3} & $\mathrm{~A}_{1}$ & 19 & 0.033 & 3078.1 & $\mathrm{~B}_{2}$ & 90.84 & 0.256 \\
\hline & & & & 3078.2 & $\mathrm{~A}_{1}$ & 21.84 & 0.062 \\
\hline & & & & 3080.2 & $\mathrm{~B}_{2}$ & 7.34 & 0.021 \\
\hline & & & & 3082.0 & $A_{1}$ & 59.18 & 0.167 \\
\hline
\end{tabular}

a The data for $\tilde{v}<2000 \mathrm{~cm}^{-1}$ have been truncated at the $10 \%$ level. The complete data are tabulated at $\langle$ http://ccf.arc.nasa.gov/ cbauschl/closed-shell.data $>$. 
greater than can be explained by this factor alone. This trend is understandable in terms of the variations in the charge distribution within the cations, and the localized nature of the $\mathrm{CH}$ stretching modes. In general, extensive electron delocalization within these species leads to an effective distribution of the positive charge throughout the molecule. Consequently, the charge density across the cation decreases in proportion to the area of the PAH structure. The $\mathrm{CH}$ bonds (and their associated stretching modes), on the other hand, are confined to the periphery of the structure and, therefore, increase in number only in proportion to the circumference of the molecule. Thus, as the size of the cation increases, the increase in the number of $\mathrm{CH}$ groups cannot completely compensate for the reduced charge density and there is a steady decrease in the net oscillating charge associated with the $\mathrm{CH}$ stretching vibrations. This implies that the character of the $\mathrm{CH}$ stretching vibrations in the cation should approach that of the neutral species with increasing molecular size. This is exactly what is reflected in the spectrum in the form of a substantial relaxation of the dramatic suppression that these modes experience upon ionization [27,35,36,39-55].

It should be noted that this effect is not expected to appreciably impact the other classes of vibrations within the molecule. The $\mathrm{CC}$ stretching modes, for example, typically involve the entire carbon skeleton of the molecule. Thus, the region associated with these modes scales as the area of the molecule, neutralizing the effect of the charge dilution. Furthermore, despite the fact that the $\mathrm{CH}$ in-plane bends, in principle, depend on the number of $\mathrm{CH}$ groups, these modes mix much more effectively with the CC stretches and, again, the effect of charge dilution is largely nullified. Finally, the intensities of the $\mathrm{CH}$ out-of-plane modes are similar between the cation and the neutral species and, consequently, little variation would be expected to accompany a transition from cation to quasi-neutral character in the $\mathrm{CH}$ groups.

\subsection{Protonated PAH Cations $\left(H P A H^{+}\right)$}

In recent selected-ion flow tube experiments, Le Page et al. [23] and Snow et al. [24] explored the reactivity of ionized PAH structures with various simple atomic and molecular species of interstellar relevance. Of particular interest, they found that the radical cations of benzene, naphthalene, and pyrene reacted readily with atomic hydrogen, but were relatively unreactive toward molecular hydrogen. Furthermore, the $\mathrm{HPAH}^{+}$species thus formed were found to be relatively unreactive toward additional $\mathrm{H}$ atoms. Note that, while reaction with a hydrogen atom is not strictly a protonation reaction (i.e. the addition of $\mathrm{H}^{+}$), the product in this case $\left(\mathrm{HPAH}^{+}\right)$is identical to that obtained from the addition of a proton to a neutral PAH molecule, and thus is referred to here as a 'protonated' PAH. These results are consistent with the studies of Weilmunster et al. described in Section 3.1, which also bear on this issue. In those studies, in contrast to the $\mathrm{C}_{\text {odd }} \mathrm{PAH}$ cations, the $\mathrm{PAH}$ cations containing an even number of carbon atoms were found to exist predominantly in the protonated form. Together, these experiments indicate that $\mathrm{PAH}$ radical cations readily add an $\mathrm{H}$ atom while closed-shell ion structures do not.

These results are again understandable in terms of the electronic structures of the ions involved. The radical cations, with their highly reactive, openshell structures, readily add a hydrogen atom (also having a single, unpaired electron) to produce a cation with a more favorable closed-shell electron configuration. The resultant protonated cation is far less reactive with $\mathrm{H}$ atoms because it already has the preferred closed-shell electronic structure and addition of another $\mathrm{H}$ atom would thus disrupt this favorable configuration. The theoretical calculations carried out here are consistent with this interpretation. For example, consider the sequential addition of $\mathrm{H}$ atoms to the naphthalene radical cation $\left(\mathrm{C}_{10} \mathrm{H}_{8}^{+}\right)$. While calculations at the B3LYP/ 4-31G level reveal no barrier to the addition of an $\mathrm{H}$ atom to the naphthalene radical cation, they do qualitatively indicate the presence of a barrier to the addition of a second hydrogen atom (forming $\mathrm{C}_{10} \mathrm{H}_{9}^{+}$and $\mathrm{C}_{10} \mathrm{H}_{10}^{+}$, respectively). The experimental results indicate that this barrier must be of sufficient magnitude to measurably affect the reactivity of these species even at large thermal energies (i.e. in a flame). The calculations further indicate that, while there is no barrier to the addition of a 


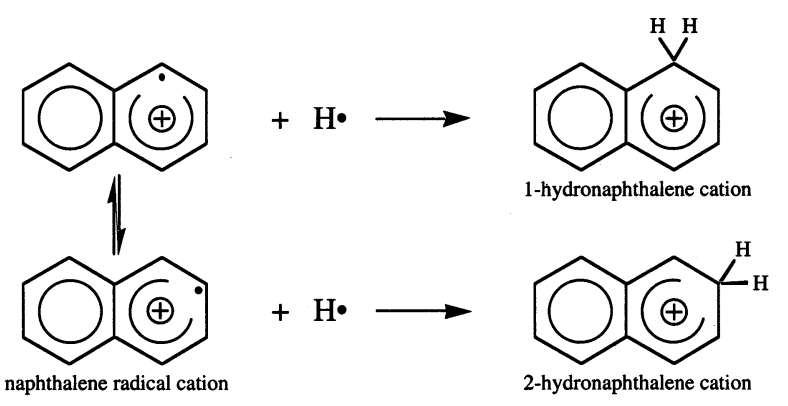

Fig. 4. An illustration of the reaction of the naphthalene radical cation $\left(\mathrm{C}_{10} \mathrm{H}_{8}^{+}\right)$with atomic hydrogen showing the two possible structural isomers of the hydronaphthalene cation product.

third $\mathrm{H}$ atom, there is once again a barrier to the addition of a fourth (forming $\mathrm{C}_{10} \mathrm{H}_{11}^{+}$and $\mathrm{C}_{10} \mathrm{H}_{12}^{+}$, respectively). Again, this is presumably a reflection of the inherently greater reactivity of the open-shell electronic structure. Thus, in general, once formed, the closed-shell, protonated PAH structure represents a bottleneck in the further hydrogenation of interstellar PAH cations, moderating the degree of hydrogenation achieved by the interstellar $\mathrm{PAH}$ population and favoring those $\mathrm{H}_{\mathrm{n}} \mathrm{PAH}^{+}$species in which $n$ is odd. Nevertheless, given the great interstellar abundance of hydrogen, the formation of hydrogenated PAH cations with some modest loss of aromatic character is expected to be a natural consequence of the presence of PAH ions in the ISM.

Consider again the reaction between the naph- thalene radical cation, $\mathrm{C}_{10} \mathrm{H}_{8}^{+}$, and an $\mathrm{H}$ atom. This reaction and the topology of its associated potential energy surface are illustrated in Figs. 4 and 5 , respectively. The calculations indicate that the $\mathrm{C}_{10} \mathrm{H}_{8}^{+}+\mathrm{H}$ reaction is exothermic by 259 $\mathrm{kJ} / \mathrm{mol}$. Thus, in the absence of a reaction barrier, the rapid reaction observed in the laboratory is understandable $[23,24,62]$. As already discussed, the primary driving force for this reaction lies in the pairing of the parent radical cation's odd electron. It should be emphasized that these and the other protonated PAH cations discussed later do not arise merely from an electrostatic attraction between the $\mathrm{H}$ atom and the $\mathrm{PAH}$ cation, but are, in fact, fully covalently bound ions. Consequently, the adsdition reaction results in the formation of an aliphatic $\mathrm{sp}^{3}$-hybridized carbon atom that no longer participates in the delocalized $\pi$ molecular orbital of the aromatic carbon skeleton, reducing the aromaticity of the parent PAH. Inspection of Fig. 4 reveals that, for naphthalene, there are two chemically distinct products of $\mathrm{H}$ atom addition: 1-and 2-hydronaphthalene cation, with the former more stable by $13.4 \mathrm{~kJ} / \mathrm{mol}$. The calculations indicate that there is no significant barrier to $\mathrm{H}$-atom addition at either of the two possible sites, and that the barrier to isomerization between the two structures $(\approx 71 \mathrm{~kJ} / \mathrm{mol})$ is small compared with the energy liberated in the $\mathrm{H}$ addition reaction (see Fig. 5). Together, these results imply that the two isomers would probably be formed in roughly the statistical ratio (1:1)

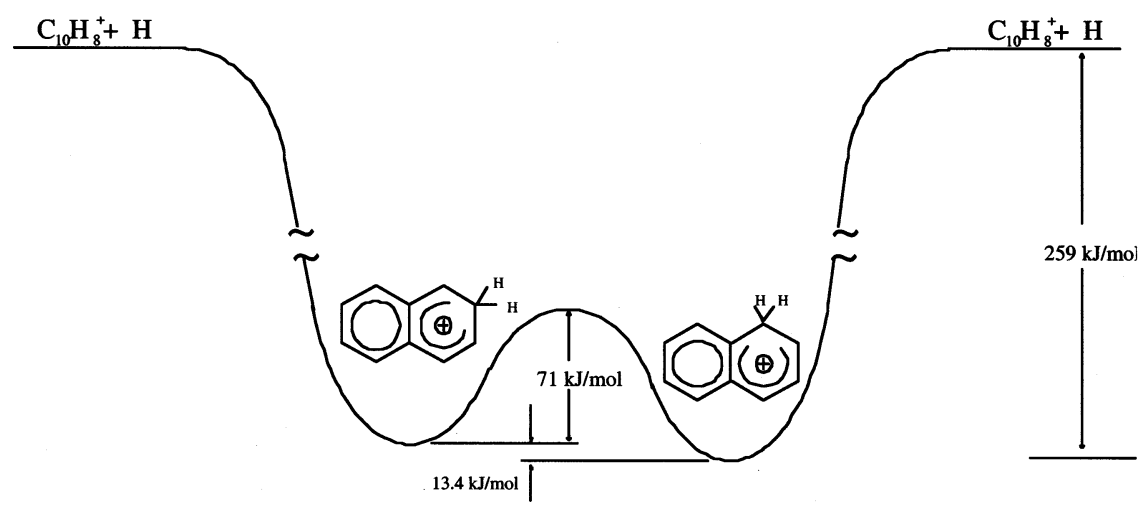

Fig. 5. A potential energy diagram for the $\mathrm{C}_{10} \mathrm{H}_{8}^{+}{ }^{\circ}+\mathrm{H}^{\bullet}$ reaction. All numerical values were obtained using DFT at the B3LYP/4-31G level. 


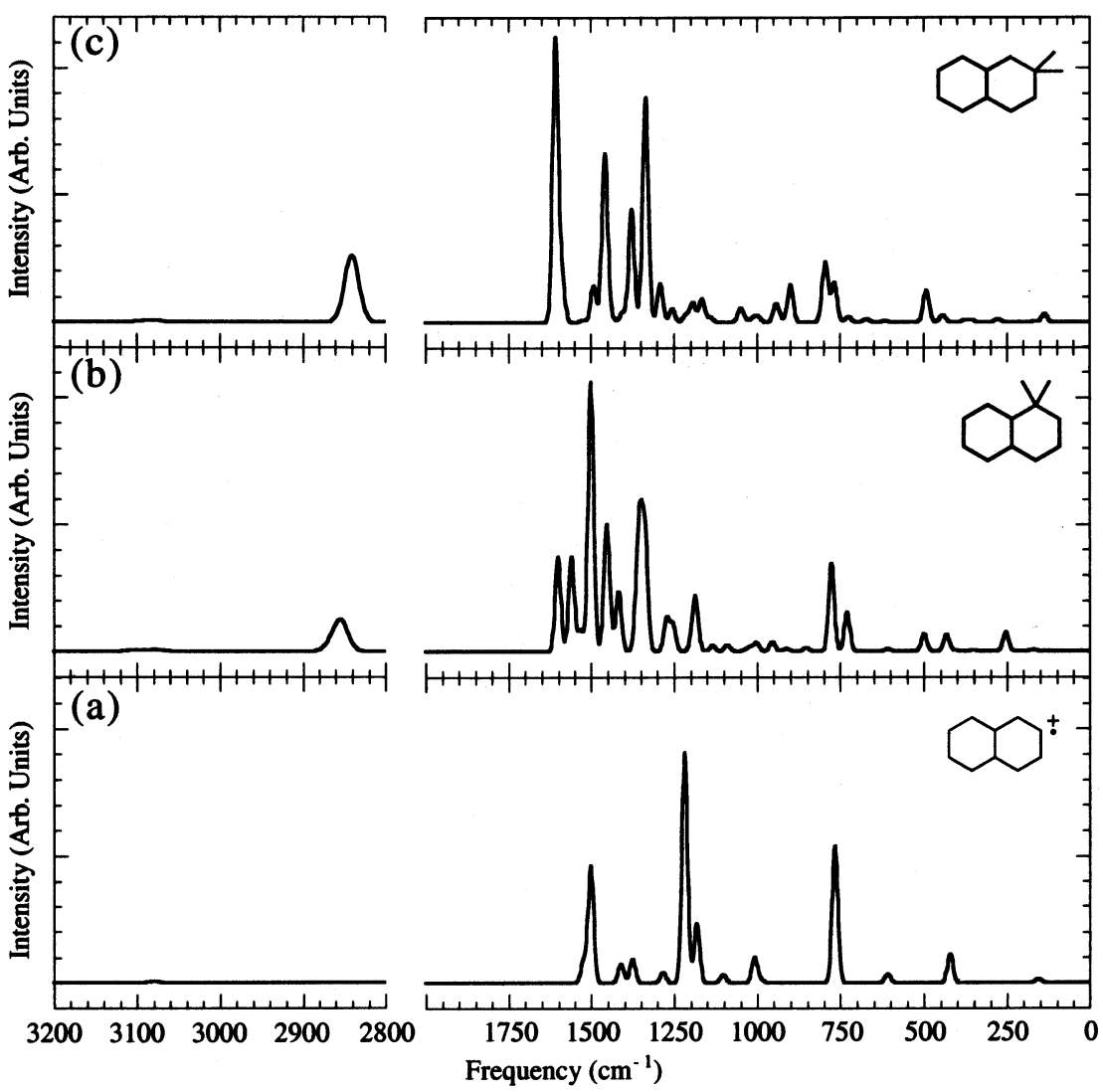

Fig. 6. The B3LYP computed IR spectra of the (b) 1-hydronaphthalene and (c) 2-hydronaphthalene cations (both $\left.\mathrm{C}_{10} \mathrm{H}_{9}^{+}\right)$compared with that of the naphthalene radical cation, $\mathrm{C}_{10} \mathrm{H}_{8}^{+}$(a). Full-width at half-maximum (FWHM), $20 \mathrm{~cm}^{-1}$.

under interstellar conditions. The sequential addition of a second hydrogen atom to form the 1,2-dihydronaphthalene cation is exothermic by another $178 \mathrm{~kJ} / \mathrm{mol}$ but, as already discussed, faces a significant reaction barrier and proceeds at a rate some two orders of magnitude less at room temperature [23,24].

Analogous calculations have been performed for the pyrene, coronene, and circumcoronene radical cations $\left(\mathrm{C}_{16} \mathrm{H}_{10}^{+}, \mathrm{C}_{24} \mathrm{H}_{12}^{+}\right.$, and $\mathrm{C}_{54} \mathrm{H}_{18}^{+}$, respectively), with similar results. As was the case for the naphthalene radical cation, hydrogen atom addition to these cations is exothermic by 251, 229 , and $234 \mathrm{~kJ} / \mathrm{mol}$, respectively. Examples of the types of structures found in the resulting protonated PAH species are presented in Fig. 2. The pyrene cation has three non-equivalent sites for $\mathrm{H}$ atom addition, yielding three unique prod- ucts: 1-hydropyrene, 2-hydropyrene, and 4-hydropyrene $\left(\mathrm{C}_{16} \mathrm{H}_{11}^{+}\right)$. The most stable product is the 1-hydropyrene, with the 2- and 4-hydropyrenes lying 63.2 and $45.2 \mathrm{~kJ} / \mathrm{mol}$ higher in energy, respectively. For the coronene cation, all the positions for $\mathrm{H}$ atom addition are equivalent, yielding only one chemically unique protonated cation structure $\left(\mathrm{C}_{24} \mathrm{H}_{13}^{+}\right)$. For the circumcoronene cation, there are again two possible non-equivalent products, 1- and 3-hydrocircumcoronene $\left(\mathrm{C}_{54} \mathrm{H}_{19}^{+}\right)$. In this case, the 3-hydrocircumcoronene is calculated to be the lower energy structure, with the 1-hydrocircumcoronene lying $52.3 \mathrm{~kJ} / \mathrm{mol}$ higher in energy.

Representations of the calculated infrared spectra of the 1- and 2-hydronaphthalene cations are shown in Fig. 6, and the salient band positions and intensities are tabulated in Table 4. For refer- 
ence, the spectrum of the naphthalene cation is also shown in the figure. The spectra of the 1-, 2-, and 4-hydropyrene cations are shown together with that of the parent pyrene cation in Fig. 7. The prominent band positions and intensities for the protonated species are presented in Table 5. The spectrum of the 1-hydrocoronene cation is shown referenced to that of the parent coronene cation in Fig. 8, and tabulated in Table 6. The spectra of the 1- and 3-hydrocircumcoronene cations are shown in Fig. 9 and the positions of the prominent bands in these spectra are reported in Table 7. The spectra of neutral circumcoronene and the circumcoronene radical cation have not been reported previously and are also included in Fig. 9. The salient bands of these species are summarized Table 8 . In all cases, spectral simulations were generated by assigning each calculated band a $20 \mathrm{~cm}^{-1} \mathrm{FWHH}$ gaussian profile of the appropriate intensity. In addition, in accordance with space limitations, the data for $\tilde{v}<2000 \mathrm{~cm}^{-1}$ have been truncated at the $10 \%$ level in the tables. However, the infrared active modes in the 3200$2800 \mathrm{~cm}^{-1}$ region are reported in their entirety. Complete tabulations of the calculated data (including both IR active and inactive modes) have been posted on the Internet at 〈http:// ccf.arc.nasa.gov/ cbauschl/closed-shell.data $\rangle$.

Again, as has been the case for PAH radical cations and the $\mathrm{C}_{\text {odd }}$ cations already presented, these spectra are all dominated by the aromatic $\mathrm{CC}$ stretching and $\mathrm{CH}$ in-plane wagging modes in the $1600-1200 \mathrm{~cm}^{-1}$ region. Inspection of Figs. 6-9 shows that, in general, the spectra of the protonated PAHs considered here are substantially more complicated than those of the $\mathrm{C}_{\text {odd }}$ cations discussed in Section 3.1. Indeed, comparison of the spectra of the protonated species with that of their parent radical cation indicates that $\mathrm{H}$ atom addition is accompanied by a marked increase in spectral complexity through this region. This is not surprising since $\mathrm{H}$ atom addition

Table 4

Calculated frequencies, symmetries, and intensities for the infrared active modes of the 1-hydronaphthalene and 2-hydronaphthalene cations, $\mathrm{C}_{10} \mathrm{H}_{9}^{+\mathrm{a}}$

\begin{tabular}{|c|c|c|c|c|c|c|c|}
\hline \multicolumn{4}{|c|}{ 1-Hydronaphthalene } & \multicolumn{4}{|c|}{ 2-Hydronaphthalene } \\
\hline$\tilde{v}\left(\mathrm{~cm}^{-1}\right)$ & Symmetry & Intensity $(\mathrm{km} / \mathrm{mol})$ & $I_{\text {rel }}$ & $\tilde{v}\left(\mathrm{~cm}^{-1}\right)$ & Symmetry & Intensity $(\mathrm{km} / \mathrm{mol})$ & $I_{\text {rel }}$ \\
\hline 729.9 & $\mathrm{~A}^{\prime \prime}$ & 28.71 & 0.128 & 766.8 & $\mathrm{~A}^{\prime \prime}$ & 30.09 & 0.127 \\
\hline 776.3 & $\mathrm{~A}^{\prime \prime}$ & 73.53 & 0.327 & 794.1 & $\mathrm{~A}^{\prime \prime}$ & 46.94 & 0.198 \\
\hline 1187.1 & $\mathrm{~A}^{\prime}$ & 26.61 & 0.118 & 1290.8 & $\mathrm{~A}^{\prime}$ & 32.43 & 0.136 \\
\hline 1271.5 & $\mathrm{~A}^{\prime}$ & 28.03 & 0.125 & 1334.2 & $\mathrm{~A}^{\prime}$ & 179.50 & 0.755 \\
\hline 1336.2 & $\mathrm{~A}^{\prime}$ & 91.12 & 0.406 & 1377.5 & $\mathrm{~A}^{\prime}$ & 94.48 & 0.398 \\
\hline 1351.2 & $\mathrm{~A}^{\prime}$ & 89.74 & 0.399 & 1457.8 & $\mathrm{~A}^{\prime}$ & 141.20 & 0.594 \\
\hline 1361.8 & $\mathrm{~A}^{\prime}$ & 34.68 & 0.154 & 1491.9 & $\mathrm{~A}^{\prime}$ & 31.05 & 0.131 \\
\hline 1416.4 & $\mathrm{~A}^{\prime}$ & 50.41 & 0.224 & 1586.9 & $\mathrm{~A}^{\prime}$ & 36.02 & 0.152 \\
\hline 1453.0 & $\mathrm{~A}^{\prime}$ & 106.28 & 0.473 & 1606.9 & $\mathrm{~A}^{\prime}$ & 237.63 & 1.00 \\
\hline 1500.1 & $\mathrm{~A}^{\prime}$ & 224.69 & 1.00 & & & & \\
\hline 1558.9 & $\mathrm{~A}^{\prime}$ & 80.12 & 0.357 & & & & \\
\hline 1599.9 & $\mathrm{~A}^{\prime}$ & 79.08 & 0.352 & & & & \\
\hline 2854.2 & $\mathrm{~A}^{\prime}$ & 24.01 & 0.107 & 2839.5 & $\mathrm{~A}^{\prime}$ & 46.62 & 0.196 \\
\hline 2865.7 & $\mathrm{~A}^{\prime \prime}$ & 6.36 & 0.028 & 2844.0 & $\mathrm{~A}^{\prime \prime}$ & 10.13 & 0.043 \\
\hline 3075.0 & $\mathrm{~A}^{\prime}$ & 0.39 & 0.002 & 3062.7 & $\mathrm{~A}^{\prime}$ & 0.33 & 0.001 \\
\hline 3079.0 & $\mathrm{~A}^{\prime}$ & 1.00 & 0.004 & 3079.0 & $\mathrm{~A}^{\prime}$ & 1.39 & 0.006 \\
\hline 3080.1 & $\mathrm{~A}^{\prime}$ & 0.15 & 0.001 & 3093.8 & $\mathrm{~A}^{\prime}$ & 0.33 & 0.001 \\
\hline 3091.3 & $\mathrm{~A}^{\prime}$ & 0.65 & 0.003 & 3097.1 & $\mathrm{~A}^{\prime}$ & 0.52 & 0.002 \\
\hline 3107.3 & $\mathrm{~A}^{\prime}$ & 0.76 & 0.003 & 3107.8 & $\mathrm{~A}^{\prime}$ & 0.19 & 0.001 \\
\hline
\end{tabular}

\footnotetext{
a The data for $\tilde{v}<2000 \mathrm{~cm}^{-1}$ have been truncated at the $10 \%$ level. The complete data are tabulated at $\langle$ http://ccf.arc.nasa.gov/ cbauschl/closed-shell.data $>$.
} 


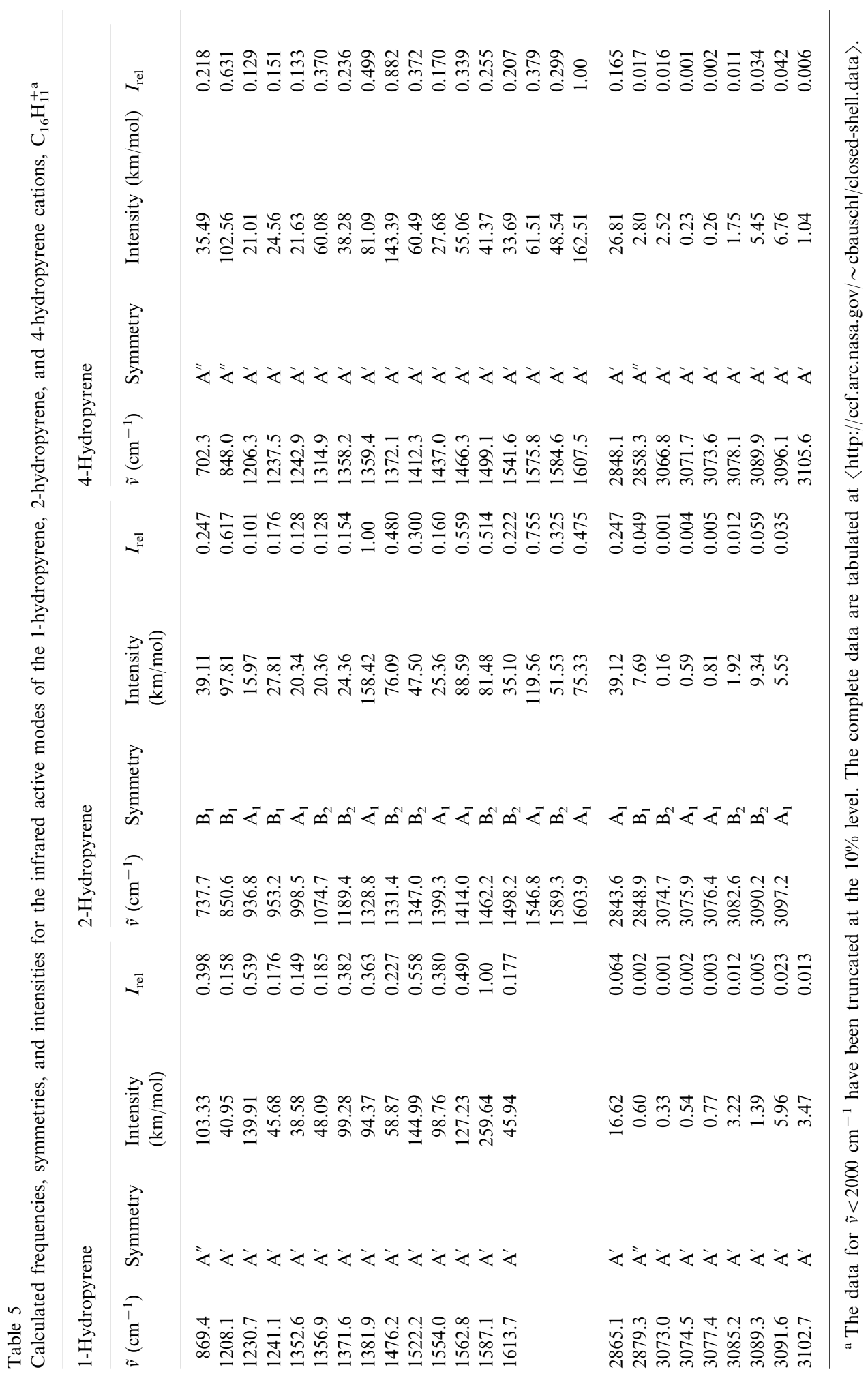




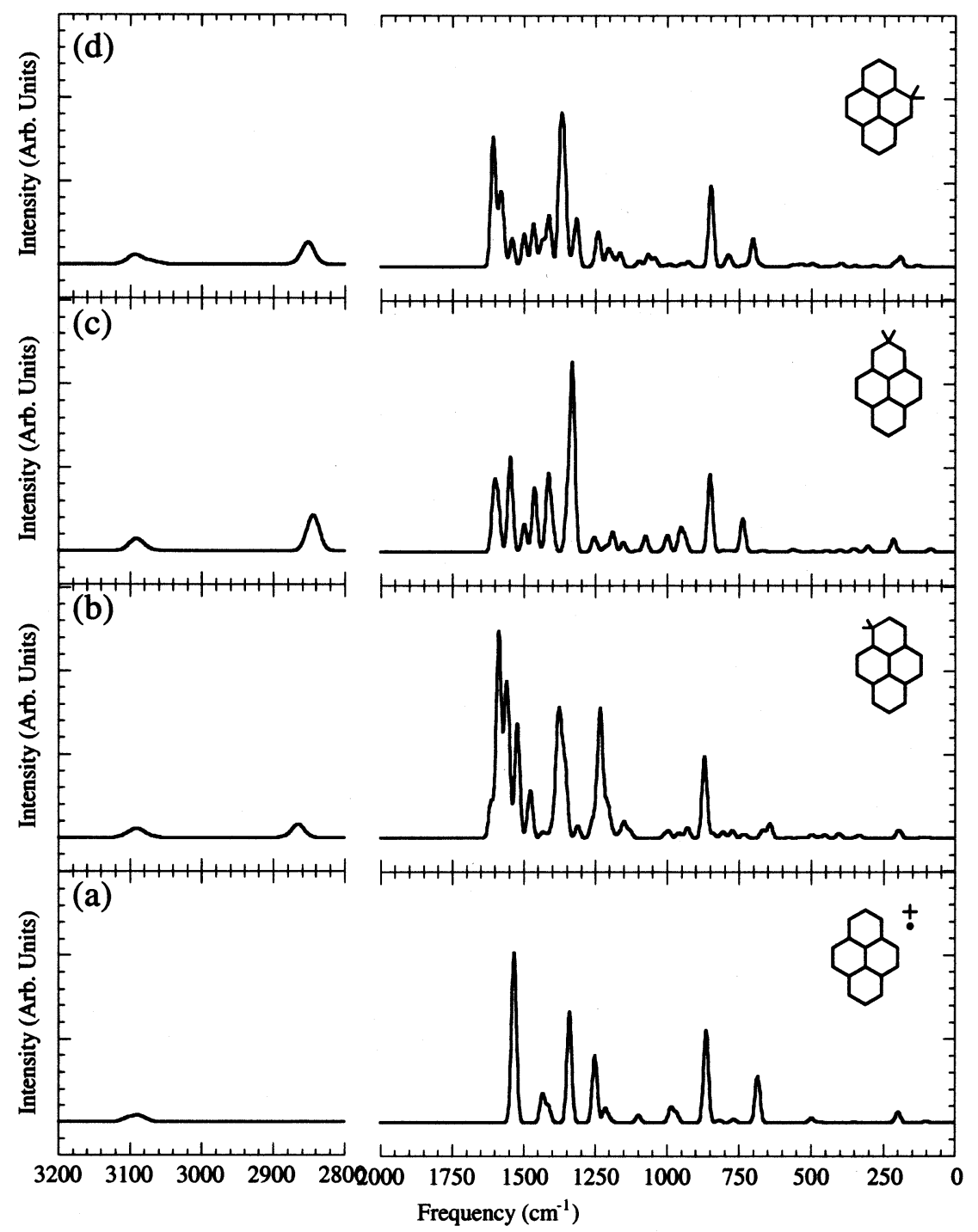

Fig. 7. The B3LYP computed IR spectra of the pyrene radical cation, $\mathrm{C}_{16} \mathrm{H}_{10}^{+}$(a), is shown together with the spectra of (b) the 1-hydropyrene cation, (c) the 2-hydropyrene cation, and (d) the 4-hydropyrene cation (all $\mathrm{C}_{16} \mathrm{H}_{11}^{+}$). $\mathrm{FWHM} 20 \mathrm{~cm}^{-1}$.

reduces the molecular symmetry, thereby increasing the number of infrared active modes and/or enhancing the IR activity of previously weak modes in the region. In addition, the characteristic deformation modes of the aliphatic $-\mathrm{CH}_{2}-$ group in the protonated species also contribute in this region, although these modes mix effectively with the aromatic modes such that there is not a clear distinction between 'aromatic' and 'aliphatic' modes. This increase in spectral complexity is also accompanied by an appreciable redistribution of the total intensity amongst the modes in this region. For example, while the total intensities of both the 1-hydro- and 3-hydrocircumcoronene cations (both $\approx 3500 \mathrm{~km} / \mathrm{mol}$ ) are similar to that of the parent circumcoronene radical cation $(\approx$ $3700 \mathrm{~km} / \mathrm{mol}$ ), the intensity of the strongest individual band in the spectrum of the 1- and 3-hydrocircumcoronene cations $\left(1576.0 \mathrm{~cm}^{-1} /\right.$ $196.5 \mathrm{~km} / \mathrm{mol}$ and $1577.9 \mathrm{~cm}^{-1} / 327.6 \mathrm{~km} / \mathrm{mol}$, 
respectively; Table 7) are three- to fivefold weaker than the strongest band in the spectrum of the circumcoronene radical cation $\left(1571.2 \mathrm{~cm}^{-1} /\right.$ $958.1 \mathrm{~km} / \mathrm{mol}$; Table 8). Clearly, a significant fraction of the intensity that is concentrated in the $1571.2 \mathrm{~cm}^{-1}$ mode of the circumcoronene radical cation has been redistributed over the manifold of new infrared active modes in the hydrocircumcoroenene cations. Similar behavior is also found between the 1-hydrocoronene cation and the coronene radical cation.

For those species that have more than one chemically unique site, the spectral structure in the $1600-1200 \mathrm{~cm}^{-1}$ region is quite sensitive to the position of the added $\mathrm{H}$ atom. This effect is greatest for the smaller hydronaphthalene and hydropyrene cations, where the added $\mathrm{H}$ atom has a relatively greater impact of on the vibrational modes. Nevertheless, the differences between the spectra of the two hydrocircumcoronene cations are not inconsequential. Furthermore, it should be emphasized that this effect is not simply due to differences in the symmetry of the species in question. For example, the 1- and 2-hydronaphthalene cations share the same $\mathrm{C}_{\mathrm{s}}$ symmetry, yet their spectra (Fig. 6b,c) are widely disparate through the $1600-1200 \mathrm{~cm}^{-1}$ region. The same is also true for the 1- and 4-hydropyrene cations whose spectra are shown in Fig. 7b,d.

Another aspect of the infrared spectra of protonated PAHs that warrants discussion is the $\mathrm{CH}$ stretching region between 3200 and $2800 \mathrm{~cm}^{-1}$. Comparison of this region of the spectra in Figs. 6-9 shows that there is a marked increase in the relative strength in the aromatic $\mathrm{CH}$ stretching feature near $3100 \mathrm{~cm}^{-1}(3.23 \mu \mathrm{m})$ compared with the aliphatic $\mathrm{CH}$ stretching feature near 2850 $\mathrm{cm}^{-1}(3.51 \mu \mathrm{m})$ with increasing molecular size. In the spectra of the 1- and 2-hydronaphthalene cations, the $\mathrm{CH}$ stretching region is dominated by the aliphatic feature of the single $-\mathrm{CH}_{2}-$ group near $2850 \mathrm{~cm}^{-1}(3.5 \mu \mathrm{m})$, while the aromatic $\mathrm{CH}$ stretching feature near $3050 \mathrm{~cm}^{-1}(3.28 \mu \mathrm{m})$ is so weak as to be all but invisible. However, the relative intensity of the aromatic feature increases relative to the aliphatic feature in the hydropyrenes and actually dominates the aliphatic feature in the spectra of the hydrocoronene and hydrocircumcoronene cations. Indeed, such a trend is expected simply on the basis of the steady increase

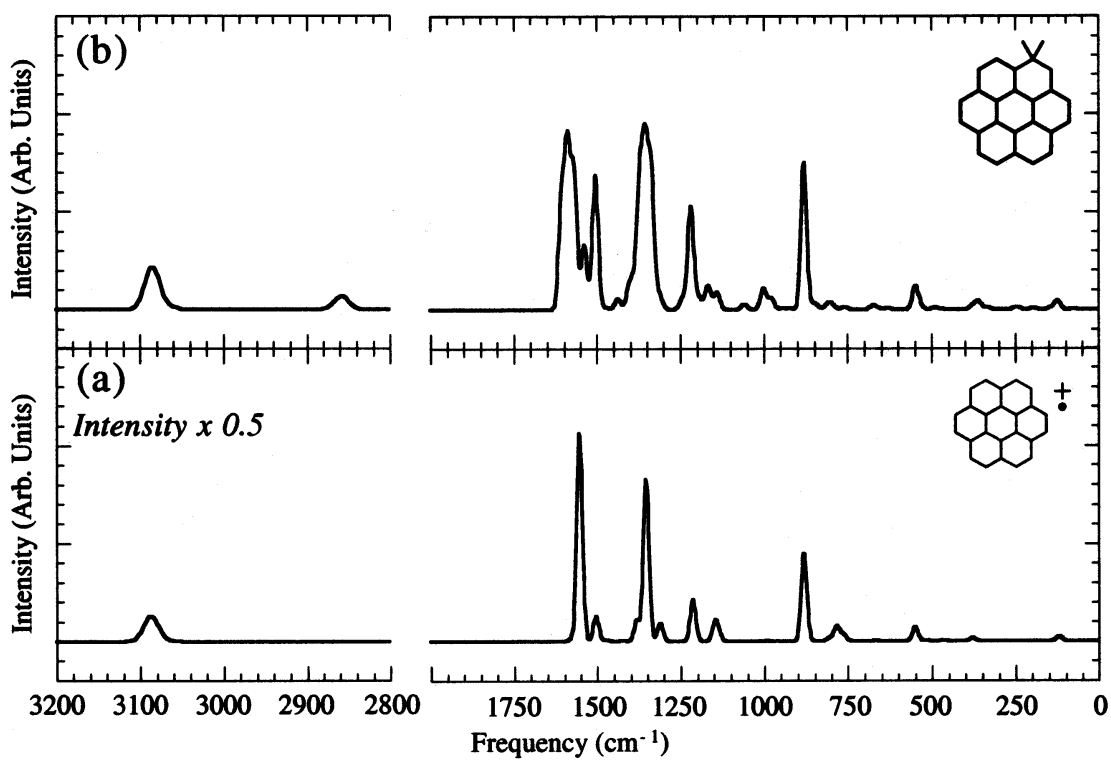

Fig. 8. The B3LYP computed IR spectra of the 1-hydrocoronene cation, $\mathrm{C}_{24} \mathrm{H}_{13}^{+}$(b), is shown compared with that of the coronene cation, $\mathrm{C}_{24} \mathrm{H}_{12}^{+}$(a). FWHM, $20 \mathrm{~cm}^{-1}$. The coronene radical cation spectrum has been scaled by 0.5 to facilitate its presentation on the same scale as the hydrocoronene cation. 
Table 6

Calculated frequencies, symmetries, and intensities for the infrared active modes of the 1-hydrocoronene cation, $\mathrm{C}_{24} \mathrm{H}_{13}^{+a}$

1-Hydrocoronene

\begin{tabular}{rlrl}
\hline$\tilde{v}\left(\mathrm{~cm}^{-1}\right)$ & Symmetry & Intensity $(\mathrm{km} / \mathrm{mol})$ & $I_{\text {rel }}$ \\
\hline 548.3 & $\mathrm{~A}^{\prime \prime}$ & 24.68 & 0.155 \\
880.1 & $\mathrm{~A}^{\prime \prime}$ & 159.27 & 1.00 \\
1001.0 & $\mathrm{~A}^{\prime}$ & 22.58 & 0.142 \\
1209.5 & $\mathrm{~A}^{\prime}$ & 21.12 & 0.133 \\
1218.3 & $\mathrm{~A}^{\prime}$ & 70.47 & 0.442 \\
1220.9 & $\mathrm{~A}^{\prime}$ & 29.58 & 0.186 \\
1335.7 & $\mathrm{~A}^{\prime}$ & 137.44 & 0.863 \\
1349.5 & $\mathrm{~A}^{\prime}$ & 67.75 & 0.425 \\
1356.1 & $\mathrm{~A}^{\prime}$ & 112.10 & 0.704 \\
1367.7 & $\mathrm{~A}^{\prime}$ & 48.63 & 0.305 \\
1372.7 & $\mathrm{~A}^{\prime}$ & 89.28 & 0.561 \\
1388.4 & $\mathrm{~A}^{\prime}$ & 21.50 & 0.135 \\
1404.4 & $\mathrm{~A}^{\prime}$ & 18.73 & 0.118 \\
1503.8 & $\mathrm{~A}^{\prime}$ & 139.25 & 0.874 \\
1538.4 & $\mathrm{~A}^{\prime}$ & 69.41 & 0.436 \\
1566.8 & $\mathrm{~A}^{\prime}$ & 130.45 & 0.819 \\
1579.9 & $\mathrm{~A}^{\prime}$ & 62.32 & 0.391 \\
1589.2 & $\mathrm{~A}^{\prime}$ & 129.54 & 0.813 \\
1596.3 & $\mathrm{~A}^{\prime}$ & 18.19 & 0.114 \\
1606.6 & $\mathrm{~A}^{\prime}$ & 107.72 & 0.676 \\
2857.5 & $\mathrm{~A}^{\prime}$ & 13.93 & 0.087 \\
2869.9 & $\mathrm{~A}^{\prime \prime}$ & 0.77 & 0.005 \\
3062.7 & $\mathrm{~A}^{\prime}$ & 0.20 & 0.001 \\
3063.5 & $\mathrm{~A}^{\prime}$ & 1.66 & 0.010 \\
3066.7 & $\mathrm{~A}^{\prime}$ & 0.30 & 0.002 \\
3067.7 & $\mathrm{~A}^{\prime}$ & 0.36 & 0.002 \\
3068.8 & $\mathrm{~A}^{\prime}$ & 0.56 & 0.004 \\
3079.9 & $\mathrm{~A}^{\prime}$ & 6.92 & 0.043 \\
3083.8 & $\mathrm{~A}^{\prime}$ & 2.15 & 0.014 \\
3084.8 & $\mathrm{~A}^{\prime}$ & 10.16 & 0.120 \\
3085.8 & $\mathrm{~A}^{\prime}$ & 19.18 & 0.063 \\
3088.4 & $\mathrm{~A}^{\prime}$ & 10.02 & \\
& & & \\
\hline & & & \\
\hline
\end{tabular}

a The data for $\tilde{v}<2000 \mathrm{~cm}^{-1}$ have been truncated at the $10 \%$ level. The complete data are tabulated at 〈http:// ccf.arc.nasa.gov/ cbauschl/closed-shell.data $>$.

in the ratio of aromatic $\mathrm{CH}$ groups to aliphatic $\mathrm{CH}$ groups (hydronaphthalene, 7/2; hydropyrene, 9/2; hydrocoronene, 11/2; hydrocircumcoronene, 17/2; see Fig. 2). However, the data in Tables 4-7 shows that the magnitude of the observed spectral change far exceeds that expected simply on the basis of the increase in the relative number of aromatic $\mathrm{CH}$ groups. In going from hydronaphthalene to hydrocircumcoronene, the ratio of the number of aromatic $\mathrm{CH}$ groups to the number of aliphatic $\mathrm{CH}$ groups increases by a factor of 2.4 (from 3.5 to 8.5). Over this same range, the calculated ratio of the total aromatic $\mathrm{CH}$ stretching intensity $\left(\Sigma\left(3110-3040 \mathrm{~cm}^{-1}\right)\right)$ to the aliphatic $\mathrm{CH}$ stretching intensity $\left(\Sigma\left(2900-2840 \mathrm{~cm}^{-1}\right)\right)$ increases from an average of 0.07 for the hydronaphthalenes to 110 for the hydrocircumcoronenes, an increase of nearly 1600 -fold. This dramatic shift arises through a combination of two concurrent effects: (1) a reduction in the total intrinsic aliphatic $\mathrm{CH}$ stretching intensity by a factor of about 20 (hydronaphthalenes, $A_{\text {aliphatic }} \approx 44 \mathrm{~km} / \mathrm{mol}$; hydrocircumcoronenes, $A_{\text {aliphatic }} \approx 2.3 \mathrm{~km} / \mathrm{mol}$ ); coupled with (2) an increase in the total intrinsic aromatic $\mathrm{CH}$ stretching intensity by a factor of nearly 100 (hydronaphthalenes, $A_{\text {aromatic }} \approx 3 \mathrm{~km} /$ mol; hydrocircumcoronenes, $A_{\text {aromatic }} \approx 250 \mathrm{~km} /$ $\mathrm{mol})$. The enhancement in the intensity of the aromatic $\mathrm{CH}$ stretching feature is very similar to that observed in the $\mathrm{C}_{\text {odd }} \mathrm{PAH}$ cations discussed in Section 3.1, and presumably shares the same origin. The suppression of the aliphatic $\mathrm{CH}$ stretching intensity is, on the other hand, more unexpected and not clearly understood at this point.

Finally, it should be noted that the spectrum of neutral circumcoronene has also been calculated as part of this work and is presented along with the cation spectra in Fig. 9. The spectrum of neutral circumcoronene has not been published previously, and it is included here for both its intrinsic merit and as a benchmark for comparison with the various related cationic species. As is typical of neutral PAHs, the spectrum is dominated by the strong aromatic $\mathrm{CH}$ stretching feature near $3060 \mathrm{~cm}^{-1}$ and the aromatic $\mathrm{CH}$ out-of-plane bending mode near $900 \mathrm{~cm}^{-1}$. Both of these features are substantially more intense than any of the $\mathrm{CC}$ stretching and $\mathrm{CH}$ in-plane bending modes in the $1600-1100 \mathrm{~cm}^{-1}$ region. Thus, the significantly increased $\mathrm{C} / \mathrm{H}$ ratio of the larger $\mathrm{PAH}$ molecule (circumcoronene, $\mathrm{C} / \mathrm{H}=3$; coronene, $\mathrm{C} / \mathrm{H}=2$; naphthalene, $\mathrm{C} / \mathrm{H}=1.25$ ) is 
not, in and of itself, sufficient to bring the ratios between the bands in these two regions into agreement with their typical interstellar values. This is consistent with the conclusion that the pattern of band intensities observed in the interstellar spectrum is indicative of a dominant contribution from 'ionized' PAHs.

\section{Astrophysical implications}

Based on the data already presented, the presence of closed-shell PAH cations in the interstellar infrared emission zones will impact the spectrum in several ways. These are now considered according to spectral region.

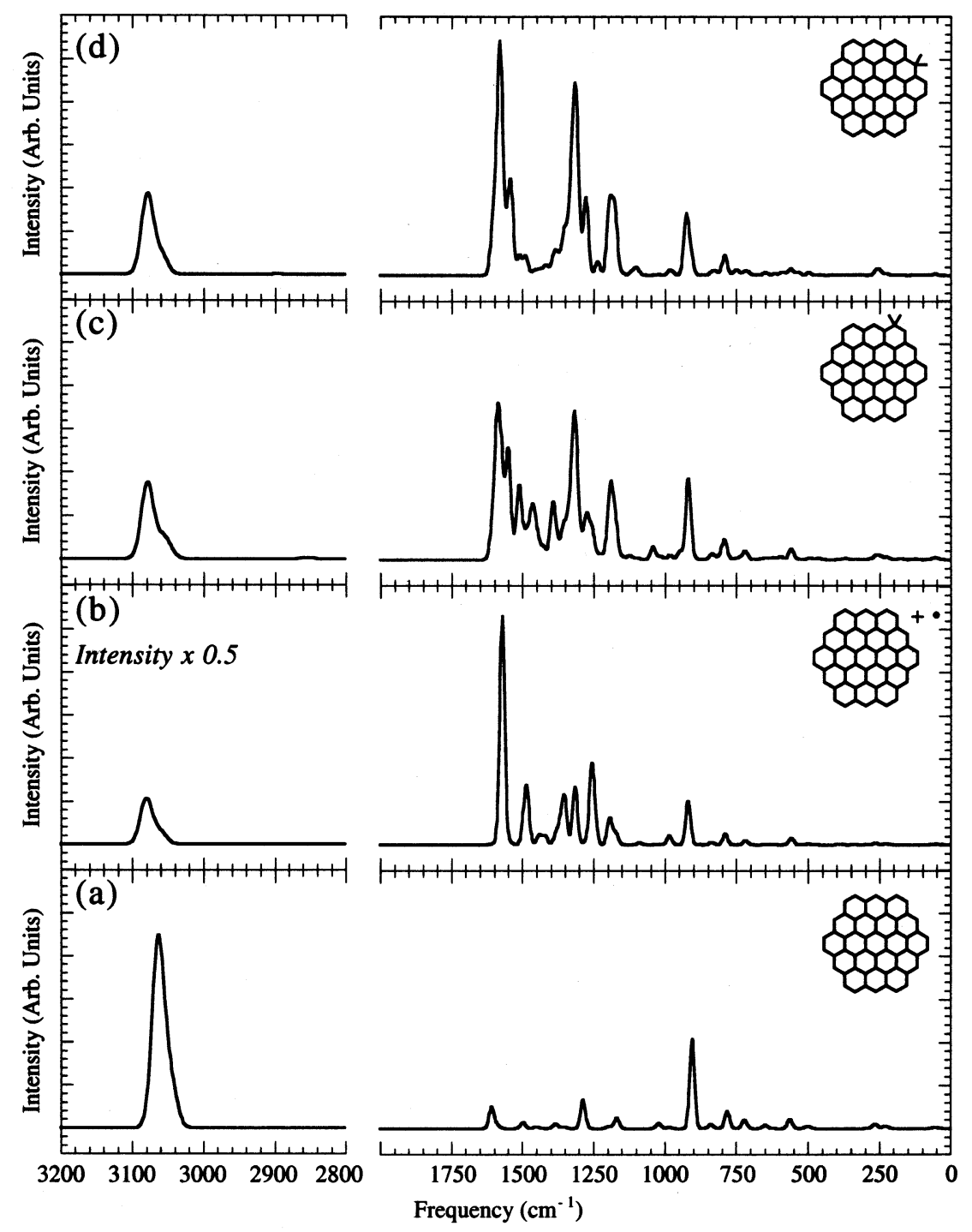

Fig. 9. The B3LYP computed IR spectra of (a) neutral circumcoronene $\left(\mathrm{C}_{54} \mathrm{H}_{18}\right)$ and (b) the circumcoronene radical cation $\left(\mathrm{C}_{54} \mathrm{H}_{18}^{+}\right)$, are compared with those of (c) the 1-hydrocircumcoronene and (d) the 3-hydrocircumcoronene cations $\left(\mathrm{C}_{54} \mathrm{H}_{19}^{+}\right)$. $\mathrm{FWHM}$, $20 \mathrm{~cm}^{-1}$. The circumcoronene radical cation spectrum has been scaled by 0.5 to facilitate its presentation on the same scale as the hydrocircumcoronene cations. 
Table 7

Calculated frequencies, symmetries, and intensities for the infrared active modes of the 1-hydrocircumcoronene and 3-hydrocircumcoronene cations, $\mathrm{C}_{54} \mathrm{H}_{19}^{+}{ }^{\text {a }}$

\begin{tabular}{|c|c|c|c|c|c|c|c|}
\hline \multicolumn{4}{|c|}{ 1-Hydrocircumcoronene } & \multicolumn{4}{|c|}{ 3-Hydrocircumcoronene } \\
\hline$\tilde{v}\left(\mathrm{~cm}^{-1}\right)$ & Symmetry & Intensity $(\mathrm{km} / \mathrm{mol})$ & $I_{\text {rel }}$ & $\tilde{v}\left(\mathrm{~cm}^{-1}\right)$ & Symmetry & Intensity $(\mathrm{km} / \mathrm{mol})$ & $I_{\text {rel }}$ \\
\hline 790.5 & $\mathrm{~A}^{\prime \prime}$ & 35.91 & 0.161 & 791.5 & $\mathrm{~B}_{1}$ & 48.31 & 0.129 \\
\hline 919.1 & $\mathrm{~A}^{\prime \prime}$ & 189.00 & 0.846 & 921.5 & $\mathrm{~B}_{1}$ & 72.02 & 0.192 \\
\hline 1041.9 & $\mathrm{~A}^{\prime}$ & 31.25 & 0.140 & 928.1 & $\mathrm{~B}_{1}$ & 86.62 & 0.231 \\
\hline 1170.3 & $\mathrm{~A}^{\prime}$ & 23.05 & 0.103 & 1176.8 & $\mathrm{~B}_{2}$ & 124.53 & 0.332 \\
\hline 1173.7 & $\mathrm{~A}^{\prime}$ & 56.61 & 0.253 & 1192.9 & $\mathrm{~A}_{1}$ & 110.37 & 0.294 \\
\hline 1184.1 & $\mathrm{~A}^{\prime}$ & 70.24 & 0.314 & 1196.0 & $\mathrm{~B}_{2}$ & 48.18 & 0.129 \\
\hline 1192.5 & $\mathrm{~A}^{\prime}$ & 126.98 & 0.568 & 1273.5 & $\mathrm{~A}_{1}$ & 40.81 & 0.109 \\
\hline 1250.0 & $\mathrm{~A}^{\prime}$ & 23.68 & 0.106 & 1276.4 & $\mathrm{~A}_{1}$ & 82.98 & 0.221 \\
\hline 1257.7 & $\mathrm{~A}^{\prime}$ & 55.63 & 0.249 & 1280.2 & $\mathrm{~A}_{1}$ & 58.54 & 0.156 \\
\hline 1273.7 & $\mathrm{~A}^{\prime}$ & 68.92 & 0.308 & 1303.4 & $\mathrm{~B}_{2}$ & 126.19 & 0.337 \\
\hline 1290.7 & $\mathrm{~A}^{\prime}$ & 29.75 & 0.133 & 1315.0 & $\mathrm{~B}_{2}$ & 374.85 & 1.00 \\
\hline 1305.1 & $\mathrm{~A}^{\prime}$ & 28.12 & 0.126 & 1329.8 & $\mathrm{~A}_{1}$ & 184.78 & 0.493 \\
\hline 1307.5 & $\mathrm{~A}^{\prime}$ & 85.81 & 0.384 & 1345.9 & $\mathrm{~B}_{2}$ & 41.32 & 0.110 \\
\hline 1317.0 & $\mathrm{~A}^{\prime}$ & 209.60 & 0.938 & 1352.8 & $\mathrm{~A}_{1}$ & 69.97 & 0.187 \\
\hline 1320.3 & $\mathrm{~A}^{\prime}$ & 93.65 & 0.419 & 1388.9 & $\mathrm{~A}_{1}$ & 43.31 & 0.116 \\
\hline 1334.5 & $\mathrm{~A}^{\prime}$ & 107.22 & 0.480 & 1511.3 & $\mathrm{~A}_{1}$ & 45.99 & 0.123 \\
\hline 1347.5 & $\mathrm{~A}^{\prime}$ & 25.35 & 0.113 & 1540.9 & $\mathrm{~B}_{2}$ & 202.38 & 0.540 \\
\hline 1354.1 & $\mathrm{~A}^{\prime}$ & 42.50 & 0.190 & 1552.6 & $\mathrm{~A}_{1}$ & 52.30 & 0.140 \\
\hline 1375.9 & $\mathrm{~A}^{\prime}$ & 22.59 & 0.101 & 1556.2 & $\mathrm{~B}_{2}$ & 44.17 & 0.118 \\
\hline 1387.8 & $\mathrm{~A}^{\prime}$ & 49.18 & 0.220 & 1572.0 & $\mathrm{~B}_{2}$ & 93.62 & 0.250 \\
\hline 1393.7 & $\mathrm{~A}^{\prime}$ & 50.79 & 0.227 & 1577.9 & $\mathrm{~A}_{1}$ & 327.63 & 0.874 \\
\hline 1395.9 & $\mathrm{~A}^{\prime}$ & 22.64 & 0.101 & 1582.4 & $\mathrm{~B}_{2}$ & 112.68 & 0.301 \\
\hline 1399.0 & $\mathrm{~A}^{\prime}$ & 22.44 & 0.100 & 1587.4 & $\mathrm{~A}_{1}$ & 99.66 & 0.266 \\
\hline 1444.6 & $\mathrm{~A}^{\prime}$ & 23.33 & 0.104 & 1596.5 & $\mathrm{~A}_{1}$ & 113.93 & 0.304 \\
\hline 1456.1 & $\mathrm{~A}^{\prime}$ & 40.47 & 0.181 & 1606.8 & $\mathrm{~B}_{2}$ & 63.94 & 0.171 \\
\hline 1465.6 & $\mathrm{~A}^{\prime}$ & 78.15 & 0.350 & & & & \\
\hline 1474.2 & $\mathrm{~A}^{\prime}$ & 23.03 & 0.103 & & & & \\
\hline 1485.8 & $\mathrm{~A}^{\prime}$ & 34.89 & 0.156 & & & & \\
\hline 1504.8 & $\mathrm{~A}^{\prime}$ & 48.40 & 0.217 & & & & \\
\hline 1512.9 & $\mathrm{~A}^{\prime}$ & 145.30 & 0.650 & & & & \\
\hline 1527.9 & $\mathrm{~A}^{\prime}$ & 22.60 & 0.101 & & & & \\
\hline 1544.2 & $\mathrm{~A}^{\prime}$ & 46.45 & 0.208 & & & & \\
\hline 1550.7 & $\mathrm{~A}^{\prime}$ & 223.51 & 1.00 & & & & \\
\hline 1566.5 & $\mathrm{~A}^{\prime}$ & 51.87 & 0.232 & & & & \\
\hline 1576.0 & $\mathrm{~A}^{\prime}$ & 196.49 & 0.879 & & & & \\
\hline 1583.9 & $\mathrm{~A}^{\prime}$ & 34.53 & 0.155 & & & & \\
\hline 1587.0 & $\mathrm{~A}^{\prime}$ & 45.68 & 0.204 & & & & \\
\hline 1590.0 & $\mathrm{~A}^{\prime}$ & 192.43 & 0.861 & & & & \\
\hline 1593.2 & $\mathrm{~A}^{\prime}$ & 26.48 & 0.118 & & & & \\
\hline 1598.2 & $\mathrm{~A}^{\prime}$ & 33.03 & 0.148 & & & & \\
\hline 1606.9 & $\mathrm{~A}^{\prime}$ & 54.35 & 0.243 & & & & \\
\hline 2854.1 & $\mathrm{~A}^{\prime}$ & 2.91 & 0.013 & 2876.3 & $\mathrm{~A}_{1}$ & 0.30 & 0.001 \\
\hline 2866.4 & $\mathrm{~A}^{\prime \prime}$ & 0.27 & 0.001 & 2897.0 & $\mathrm{~B}_{1}$ & 1.01 & 0.003 \\
\hline 3048.2 & $\mathrm{~A}^{\prime}$ & 14.74 & 0.066 & 3056.7 & $\mathrm{~A}_{1}$ & 4.55 & 0.012 \\
\hline 3054.6 & $\mathrm{~A}^{\prime}$ & 5.74 & 0.026 & 3057.6 & $\mathrm{~B}_{2}$ & 1.98 & 0.005 \\
\hline 3055.9 & $\mathrm{~A}^{\prime}$ & 4.03 & 0.018 & 3057.7 & $\mathrm{~A}_{1}$ & 5.55 & 0.015 \\
\hline 3056.7 & $\mathrm{~A}^{\prime}$ & 13.75 & 0.062 & 3058.7 & $\mathrm{~B}_{2}$ & 14.24 & 0.038 \\
\hline 3058.0 & $\mathrm{~A}^{\prime}$ & 7.49 & 0.033 & 3058.9 & $\mathrm{~A}_{1}$ & 1.24 & 0.003 \\
\hline 3059.5 & $\mathrm{~A}^{\prime}$ & 2.79 & 0.013 & 3059.9 & $\mathrm{~B}_{2}$ & 1.95 & 0.005 \\
\hline
\end{tabular}


Table 7 (Continued)

\begin{tabular}{|c|c|c|c|c|c|c|c|}
\hline \multicolumn{4}{|c|}{ 1-Hydrocircumcoronene } & \multicolumn{4}{|c|}{ 3-Hydrocircumcoronene } \\
\hline$\tilde{v}\left(\mathrm{~cm}^{-1}\right)$ & Symmetry & Intensity $(\mathrm{km} / \mathrm{mol})$ & $I_{\text {rel }}$ & $\tilde{v}\left(\mathrm{~cm}^{-1}\right)$ & Symmetry & Intensity $(\mathrm{km} / \mathrm{mol})$ & $I_{\mathrm{rel}}$ \\
\hline 3060.3 & $\mathrm{~A}^{\prime}$ & 3.91 & 0.018 & 3060.1 & $\mathrm{~A}_{1}$ & 9.91 & 0.026 \\
\hline 3060.7 & $\mathrm{~A}^{\prime}$ & 5.30 & 0.024 & 3061.0 & $\mathrm{~B}_{2}$ & 4.34 & 0.012 \\
\hline 3061.7 & $\mathrm{~A}^{\prime}$ & 4.56 & 0.020 & 3061.3 & $\mathrm{~A}_{1}$ & 1.38 & 0.004 \\
\hline 3063.1 & $\mathrm{~A}^{\prime}$ & 0.69 & 0.003 & 3062.0 & $\mathrm{~B}_{2}$ & 4.02 & 0.011 \\
\hline 3077.7 & $\mathrm{~A}^{\prime}$ & 14.93 & 0.067 & 3077.2 & $\mathrm{~B}_{2}$ & 8.38 & 0.022 \\
\hline 3078.1 & $\mathrm{~A}^{\prime}$ & 47.82 & 0.214 & 3077.3 & $\mathrm{~A}_{1}$ & 37.56 & 0.100 \\
\hline 3078.3 & $\mathrm{~A}^{\prime}$ & 53.00 & 0.237 & 3078.9 & $\mathrm{~B}_{2}$ & 0.25 & 0.001 \\
\hline 3079.0 & $\mathrm{~A}^{\prime}$ & 37.63 & 0.168 & 3079.0 & $\mathrm{~A}_{1}$ & 24.30 & 0.065 \\
\hline \multirow[t]{2}{*}{3080.8} & $\mathrm{~A}^{\prime}$ & 33.37 & 0.149 & 3079.3 & $\mathrm{~B}_{2}$ & 96.88 & 0.258 \\
\hline & & & & 3079.5 & $\mathrm{~A}_{1}$ & 29.81 & 0.080 \\
\hline
\end{tabular}

${ }^{\text {a }}$ The data for $\tilde{v}<2000 \mathrm{~cm}^{-1}$ have been truncated at the $10 \%$ level. The complete data are tabulated at $\langle$ http://ccf.arc.nasa.gov/ cbauschl/closed-shell.data $\rangle$.

\subsection{The $1600 \mathrm{~cm}^{-1}(6.2 \mu \mathrm{m})$ region}

Consistent with the behavior of $\mathrm{PAH}$ radical cations reported previously [27,39-55], the aromatic CC stretching modes that fall near 1600 $\mathrm{cm}^{-1}$, close to the prominent $6.2-6.3 \mu \mathrm{m}$ interstellar feature, are strongly enhanced in the closed-shell cations compared with the neutral species. In fact, in the spectra of the closed-shell species, this is consistently the strongest band in

Table 8

Calculated frequencies, symmetries, and intensities for for the infrared active modes of neutral circumcoronene, $\mathrm{C}_{54} \mathrm{H}_{18}$, and the circumcoronene radical cation, $\mathrm{C}_{54} \mathrm{H}_{18}^{+}$a

\begin{tabular}{|c|c|c|c|c|c|c|c|}
\hline \multicolumn{4}{|l|}{$\mathrm{C}_{54} \mathrm{H}_{18}$} & \multicolumn{4}{|l|}{$\mathrm{C}_{54} \mathrm{H}_{18}^{+}$} \\
\hline$\tilde{v}\left(\mathrm{~cm}^{-1}\right)$ & Symmetry & Intensity $(\mathrm{km} / \mathrm{mol})$ & $I_{\text {rel }}$ & $\tilde{v}\left(\mathrm{~cm}^{-1}\right)$ & Symmetry & Intensity $(\mathrm{km} / \mathrm{mol})$ & $I_{\mathrm{rel}}$ \\
\hline 782.0 & $\mathrm{~B}_{3 \mathrm{u}}$ & 43.30 & 0.188 & 919.0 & $\mathrm{~A}_{\mathrm{u}}$ & 216.85 & 0.226 \\
\hline 904.1 & $\mathrm{~B}_{3 \mathrm{u}}$ & 220.23 & 0.954 & 1246.1 & $\mathrm{~B}_{\mathrm{u}}$ & 112.78 & 0.118 \\
\hline 1286.5 & $\mathrm{~B}_{1 \mathrm{u}}$ & 34.37 & 0.149 & 1256.9 & $\mathrm{~B}_{\mathrm{u}}$ & 350.64 & 0.366 \\
\hline 1286.6 & $\mathrm{~B}_{2 \mathrm{u}}$ & 34.69 & 0.150 & 1314.8 & $\mathrm{~B}_{\mathrm{u}}$ & 286.99 & 0.300 \\
\hline 1607.9 & $\mathrm{~B}_{2 \mathrm{u}}$ & 26.17 & 0.113 & 1351.1 & $\mathrm{~B}_{\mathrm{u}}$ & 164.05 & 0.171 \\
\hline \multirow[t]{4}{*}{1608.3} & $\mathrm{~B}_{1 \mathrm{u}}$ & 26.09 & 0.113 & 1483.6 & $\mathrm{~B}_{\mathrm{u}}$ & 232.83 & 0.243 \\
\hline & & & & 1493.4 & $\mathrm{~B}_{\mathrm{u}}$ & 100.50 & 0.105 \\
\hline & & & & 1570.0 & $\mathrm{~B}_{\mathrm{u}}$ & 141.43 & 0.148 \\
\hline & & & & 1571.2 & $\mathrm{~B}_{\mathrm{u}}$ & 958.13 & 1.00 \\
\hline 3041.8 & $\mathrm{~B}_{2 \mathrm{u}}$ & 0.52 & 0.002 & 3058.4 & $\mathrm{~B}_{\mathrm{u}}$ & 9.19 & 0.010 \\
\hline 3042.0 & $\mathrm{~B}_{1 \mathrm{u}}$ & 0.50 & 0.002 & 3059.3 & $\mathrm{~B}_{\mathrm{u}}$ & 11.71 & 0.012 \\
\hline 3045.5 & $\mathrm{~B}_{1 \mathrm{u}}$ & 56.58 & 0.245 & 3060.4 & $\mathrm{~B}_{\mathrm{u}}$ & 20.79 & 0.022 \\
\hline 3046.0 & $\mathrm{~B}_{2 \mathrm{u}}$ & 51.91 & 0.225 & 3062.5 & $\mathrm{~B}_{\mathrm{u}}$ & 11.45 & 0.012 \\
\hline 3047.0 & $\mathrm{~B}_{1 \mathrm{u}}$ & 2.43 & 0.011 & 3063.3 & $\mathrm{~B}_{\mathrm{u}}$ & 9.61 & 0.010 \\
\hline 3062.8 & $\mathrm{~B}_{2 \mathrm{u}}$ & 5.31 & 0.023 & 3079.8 & $\mathrm{~B}_{\mathrm{u}}$ & 34.87 & 0.036 \\
\hline 3063.4 & $\mathrm{~B}_{1 \mathrm{u}}$ & 229.17 & 0.993 & 3080.5 & $\mathrm{~B}_{\mathrm{u}}$ & 81.22 & 0.085 \\
\hline 3063.7 & $\mathrm{~B}_{2 \mathrm{u}}$ & 230.88 & 1.00 & 3080.7 & $\mathrm{~B}_{\mathrm{u}}$ & 106.91 & 0.112 \\
\hline
\end{tabular}

a The data for $\tilde{v}<2000 \mathrm{~cm}^{-1}$ have been truncated at the $10 \%$ level. The complete data are tabulated at $\langle$ http://ccf.arc.nasa.gov/ cbauschl/closed-shell.data $>$. 
the spectrum. Of further interest, these features consistently fall at higher frequencies in the closed PAH structures than in the corresponding openshell species. For example, for circumcoronene (Fig. 9 and Table 8), the most prominent band of the closed-shell neutral species falls at $1608 \mathrm{~cm}^{-1}$ $(6.219 \mu \mathrm{m})$, while that of the radical cation falls at $1572 \mathrm{~cm}^{-1}(6.361 \mu \mathrm{m})$. Coronene also exhibits such a trend (neutral, $1602 \mathrm{~cm}^{-1}, 6.242 \mu \mathrm{m}$; radical cation, $\left.1554 \mathrm{~cm}^{-1}, 6.435 \mu \mathrm{m}\right)[27,40,44]$. Although this general trend holds for both the $\mathrm{C}_{\text {odd }}$ and protonated PAH cations considered here, the corresponding vibration falls between 1590 and $1580 \mathrm{~cm}^{-1}(6.29$ and $6.33 \mu \mathrm{m})$, still somewhat red-shifted from the band position in the parent neutral. While this falls in the red wing of the canonical $1610 \mathrm{~cm}^{-1}(6.2 \mu \mathrm{m})$ interstellar feature, it is close to the newly discovered 1590 $\mathrm{cm}^{-1}(6.29 \mu \mathrm{m})$ emission component recently resolved in the high-resolution spectra of a number of objects by the ISO satellite [65]. Overall, given the prominence of the features in this region in the spectra of the closed-shell PAH cations, if a significant population of such species is indeed present in the interstellar medium, they would certainly be expected to dominate the emission at this position.

\subsection{The $1500-1100 \mathrm{~cm}^{-1}(6.7-9 \mu \mathrm{m})$ region}

In the interstellar spectrum, this region is dominated by the strong, broad $7.7 \mu \mathrm{m}$ emission envelope and its prominent shoulder near $8.6 \mu \mathrm{m}$. Careful observations [66] have shown that this band is actually a composite of a number of overlapping features dominated by two components falling near 7.6 and $7.8 \mu \mathrm{m}$. This spectral region is diagnostic of aromatic $\mathrm{CC}$ stretching and $\mathrm{CH}$ in-plane bending motions in PAHs. Previous studies of PAH radical cations have established that these modes are strongly enhanced by ionization [27,39-55] and, not surprisingly, the results already presented confirm that this effect also holds for closed-shell cations. Unlike the consistent behavior of the bands in the $1600 \mathrm{~cm}^{-1}$ region already discussed, the direction of the ionization shift experienced by the PAH bands in this range is less predictable. For example, in the circumcoronene radical cation, the most prominent band in this region falls at $1256 \mathrm{~cm}^{-1}$ (7.962 $\mu \mathrm{m})$, red-shifted by $30 \mathrm{~cm}^{-1}$ from its position in neutral circumcoronene $\left(1286 \mathrm{~cm}^{-1}, 7.776 \mu \mathrm{m}\right.$; see Table 8). Compare this with coronene, where the most prominent band of the radical cation in this region is blue-shifted by $38 \mathrm{~cm}^{-1}$ (cation, $1350 \mathrm{~cm}^{-1}, 7.407 \mu \mathrm{m}$; neutral, $1312 \mathrm{~cm}^{-1}, 7.622$ $\mu \mathrm{m})[40,44]$. Nonetheless, there is an underlying consistency with the interstellar emission spectrum. In each case, the dominant bands tend to fall within the envelope of the interstellar $7.6 \mu \mathrm{m}$ $\left(1315 \mathrm{~cm}^{-1}\right)$ component that dominates the 7.7 $\mu \mathrm{m}$ emission envelope in HII regions and reflection nebula [66]. Indeed, inspection of the tables show that, in general, for both the $\mathrm{C}_{\text {odd }}-\mathrm{PAH}$ and $\mathrm{HPAH}^{+}$cations considered here, the dominant features in this region typically fall between 1350 and $1314 \mathrm{~cm}^{-1}$ (7.41 and $\left.7.61 \mu \mathrm{m}\right)$, most consistent with the position of the interstellar $7.6 \mu \mathrm{m}$ component. The detailed origin of the strong 7.8 $\mu \mathrm{m}$ component therefore remains unclear.

In addition to the aromatic modes that fall in this region, the $\mathrm{HPAH}^{+}$species have an additional, unique contribution in this region of the spectrum. The aliphatic $\mathrm{CH}_{2}$ deformation modes of these species are expected to fall in the mid$1400 \mathrm{~cm}^{-1}(\sim 7 \mu \mathrm{m})$ range [67]. Indeed, the greater spectral complexity that is observed throughout this region in the protonated $\mathrm{PAH}$ cations is no doubt partially attributable to the contributions of the aliphatic modes. As with the aromatic modes in this region, the aliphatic deformation modes are enhanced by ionization and are actually more intense than the strong aliphatic $\mathrm{CH}$ stretching bands (see Tables 4-7) that dominate the spectra of neutral hydrogenated PAHs. However, as already noted, these modes mix with the aromatic $\mathrm{CC}$ stretching and $\mathrm{CH}$ in-plane bending modes to such a degree that it is not possible to distinguish between 'aliphatic' and 'aromatic' modes in this region.

A final, consistent aspect of the spectra of these species with the interstellar emission spectra is the presence of a prominent band in the 1214-1140 $\mathrm{cm}^{-1}(8.24-8.77 \mu \mathrm{m})$ range that corresponds most closely to the interstellar $8.6 \mu \mathrm{m}$ (1165 $\mathrm{cm}^{-1}$ ) component of the interstellar emission 
spectrum. For the closed-shell cations considered here, the intensities of these bands relative to the dominant $1300 \mathrm{~cm}^{-1}$ bands also echos that of the interstellar emission.

\subsection{The $3200-2800 \mathrm{~cm}^{-1}(3.1-3.6 \mu \mathrm{m})$ region}

The other region in which closed-shell cations potentially impact the interstellar emission spectrum is in the $\mathrm{CH}$ stretching region between 3200 and $2800 \mathrm{~cm}^{-1}(3.1$ and $3.6 \mu \mathrm{m})$. While all of the species considered here would certainly contribute to the well-known $3.3 \mu \mathrm{m}$ emission band (aromatic $\mathrm{CH}$ stretching modes), of particular interest is the contribution of the $\mathrm{HPAH}^{+}$species to the variable emission complex that falls on the red wing of the aromatic feature between $\sim 3.4$ and $3.5 \mu \mathrm{m}$. This range is diagnostic of aliphatic $\mathrm{CH}$ stretching modes and, as expected, inspection of Figs. 6-9 shows that protonation is accompanied by the appearance of a feature that is attributable to these modes. In each of the $\mathrm{HPAH}^{+}$considered here, the aliphatic $\mathrm{CH}$ stretching region displays a pair of bands that are typically separated by $5-20 \mathrm{~cm}^{-1}$ and centered near $2860 \mathrm{~cm}^{-1}(3.5 \mu \mathrm{m})$. The distribution of intensity between these bands is variable, but in all but one case it is the lower frequency band that dominates the pair (see Tables 4-7).

The dominance of the $3.3 \mu \mathrm{m}$ aromatic $\mathrm{CH}$ stretching feature over the aliphatic $\mathrm{CH}$ stretching feature in the typical interstellar emission spectrum, despite the markedly greater intrinsic strength of the latter modes, indicates that the interstellar emitting population is predominantly aromatic with only a modest degree of aliphatic character. Given the great abundance of hydrogen in the interstellar medium and the inherent favorability of the closed-shell $\mathrm{HPAH}^{+}$species, it is tempting to posit that simple protonation across the PAH cation population might contribute sufficient aliphatic character to account for the interstellar 3.4-3.5 $\mu \mathrm{m}$ emission. This idea is, however, not borne out by the data presented in this article. As already mentioned, the protonated species discussed in Section 3.2 consistently display only a single noteworthy feature near $2860 \mathrm{~cm}^{-1}$ (3.50 $\mu \mathrm{m})$. Thus, while such species likely contribute to the interstellar emission in this region, they cannot in-and-of-themselves explain the spectral complexity that is observed in that spectrum. Instead, that complexity implies a modest subpopulation of more highly hydrogenated species $\left(\mathrm{H}_{n} \mathrm{PAHs}\right.$ and/ or their associated ions) [22].

\subsection{The $900-700 \mathrm{~cm}^{-1}(11-14 \mu \mathrm{m})$ region}

Finally, it is interesting to note that, although there are twice as many doubly-adjacent $\mathrm{CH}$ groups as non-adjacent $\mathrm{CH}$ groups in $\mathrm{C}_{59} \mathrm{H}_{19}^{+}$, the circumcoronene radical cation, and the hydrogenated circumcoronene cations, the 900-700 $\mathrm{cm}^{-1}(11-14 \mu \mathrm{m}) \mathrm{CH}$ out-of-plane bending region is dominated by only one band. That band consistently falls near $930-920 \mathrm{~cm}^{-1}(10.75-10.87 \mu \mathrm{m})$, close to the position of non-adjacent $\mathrm{CH}$ groups on open shell PAH cations that have previously been proposed as a tracer of the ionized interstellar PAH component [68].

\section{Conclusions}

Prompted by recent experimental studies that indicate such species may play an important role in the interstellar medium, we have carried out B3LYP/4/31G calculations to determine the harmonic frequencies and intensities for a variety of closed-shell PAH cations. The set of species considered extends over a wide range of molecular sizes and includes both $\mathrm{C}_{\text {odd }} \mathrm{PAH}$ cations - fully benzenoid species composed of an odd number of carbon atoms - and protonated PAHs.

Overall, the spectra of closed-shell PAH cations are consistent with previously reported theoretical and experimental spectra of PAH radical cations, and with the global pattern of band positions and intensities in the interstellar emission spectrum. The spectra do, however, display some distinctive features that distinguish them from the PAH species considered previously. The $\mathrm{C}_{\text {odd }} \mathrm{PAH}$ cation spectra, for example, display a notably weaker dependence on molecular size than is typical of either the protonated PAHs considered here or of the $\mathrm{PAH}$ radical cations that can be found the literature. Furthermore, the spectra of these species are dominated by several strong features in the 
$1600-1100 \mathrm{~cm}^{-1}$ region, the strongest of which is consistently the highest frequency band falling near $1600 \mathrm{~cm}^{-1}$. Thus, if these species are, indeed, common in the interstellar medium, they would be expected to make a disproportionate contribution to the $6.2 \mu \mathrm{m}$ infrared emission band.

The protonated PAHs tend to display a greater degree of spectral complexity compared with their parent radical cation. This is due both to a lowering of the symmetry of the cation as well as to the contributions of the characteristic aliphatic modes of the associated $\mathrm{CH}_{2}$ group.

Finally, for both classes of closed-shell PAH cations, increasing molecular size is found to be accompanied by a strong increase in the intensity of the aromatic $\mathrm{CH}$ stretching features. Analysis of the Mulliken populations indicates that this is a consequence of the decrease in charge density within the molecule as the positive charge is smeared over a larger and larger molecular skeleton. Consequently, the character of these modes, which are, in general, strongly suppressed in PAH cations, gradually approaches the dominant character of the analogous modes in neutral PAHs. In contrast, the aliphatic $\mathrm{CH}$ stretching modes of the protonated PAHs are increasingly suppressed with increasing molecular size. The origin of this effect is not yet clearly understood and will require further study.

\section{Acknowledgements}

Two of the authors (D.M.H., L.J.A.) would like to thank the editors of this issue for contributing their time and effort to organize this special journal edition. We also gratefully acknowledge support under NASA's Long Term Space Astrophysics Program (Grant 399-20-01).

\section{References}

[1] F.C. Gillett, W.J. Forrest, K.M. Merrill, Astrophys. J. 183 (1973) 87.

[2] R.W. Russell, B.T. Soifer, S.P. Willner, Astrophys. J. 217 (1977) L149.

[3] D.K. Aitken, in: C.G. Wynn-Williams, D.P. Cruikshank (Eds.), Infrared Astronomy, Reidel, Dordrecht, 1981, p. 207.
[4] S.P. Willner, in: M.F. Kessler, J.P. Phillips (Eds.), Galactic and Extragalactic Infrared Spectroscopy, Reidel, Dordrecht, 1984, p. 37.

[5] M.M. Phillips, D.K. Aitken, P.F. Roche, Mon. Not. R. Astron. Soc. 207 (1984) 25.

[6] T.R. Geballe, A.G.G.M. Tielens, S. Kwok, B.J. Hrivnak, Astrophys. J. 387 (1992) L89.

[7] P.R. Roelfsema, et al., Astron. Astrophys. 315 (1996) L289.

[8] R.J. Laureijs, et al., Astron. Astrophys. 315 (1996) L313.

[9] T. Onaka, I. Yamamura, T. Tanabe, T.L. Roellig, L. Yuen, Pub. Astron. Soc. Jpn. 48 (1996) L59.

[10] K. Matilla, et al., Astron. Astrophys. 315 (1996) L353.

[11] G.C. Sloan, J.D. Bregman, T.R. Geballe, L.J. Allamandola, C.E. Woodward, Astrophys. J. 474 (1997) 735.

[12] A. Leger, J.L. Puget, Astron. Astrophys. 137 (1984) L5.

[13] L.J. Allamandola, A.G.G.M. Tielens, J.R. Barker, Astrophys. J. 290 (1985) L25.

[14] K. Sellgren, Astrophys. J. 277 (1984) 627.

[15] M. Cohen, A.G.G.M. Tielens, L.J. Allamandola, Astrophys. J. 299 (1985) L93.

[16] M. Cohen, L.J. Allamandola, A.G.G.M. Tielens, J. Bregman, J.P. Simpson, F.C. Witteborn, D. Wooden, D. Rank, Astrophys. J. 302 (1986) 737.

[17] M. Cohen, A.G.G.M. Tielens, J. Bregman, F.C. Witteborn, D. Rank, L.J. Allamandola, D. Wooden, M. DeMuizon, Astrophys. J. 341 (1989) 246.

[18] W. Schutte, A.G.G.M. Tielens, L.J. Allamandola, Astrophys. J. 415 (1993) 397.

[19] E.L.O. Bakes, A.G.G.M. Tielens, Astrophys. J. 427 (1994) 822.

[20] F. Salama, E.L.O. Bakes, L.J. Allamandola, A.G.G.M. Tielens, Astrophys. J. 458 (1996) 621.

[21] H.W. Jochims, E. Ruhl, H. Baumgartel, S. Tobita, S. Leach, Astrophys. J. 420 (1994) 307.

[22] M.P. Bernstein, S.A. Sandford, L.J. Allamandola, Astrophys. J. 472 (1996) L127.

[23] V. LePage, Y. Keheyan, V. Bierbaum, T. Snow, J. Am. Chem. Soc. 119 (1997) 8373.

[24] T. Snow, V. Le Page, Y. Keheyan, V. Bierbaum, Nature 391 (1997) 259.

[25] E.L.O. Bakes, A.G.G.M. Tielens, Astrophys. J. 499 (1998) 258.

[26] L.J. Allamandola, A.G.G.M. Tielens, J.R. Barker, Astrophys. J. Suppl. Ser. 71 (1989) 733.

[27] D.J. DeFrees, M.D. Miller, in: L.J. Allamandola, A.G.G.M. Tielens (Eds.), Interstellar Dust: Contributed Papers, NASA CP 3036, 1989, p. 173.

[28] J.D. Brenner, J.R. Barker, Astrophys. J. 388 (1992) L39.

[29] F. Pauzat, D. Talbi, M.D. Miller, D.J. DeFrees, Y. Ellinger, J. Phys. Chem. 96 (1992) 7882.

[30] D.J. DeFrees, M.D. Miller, D. Talbi, F. Pauzat, Y.J. Ellinger, Astrophys. J. 408 (1993) 530.

[31] J. Szczepanski, M. Vala, Nature 363 (1993) 699.

[32] F. Salama, C. Joblin, L.J. Allamandola, J. Chem. Phys. 101 (1994) 10252. 
[33] D. Hudgins, S.A. Sandford, L.J. Allamandola, J. Phys. Chem. 98 (1994) 4243.

[34] S. Schlemmer, D.J. Cook, J.A. Harrison, B. Wurfel, W. Chapman, R.J. Saykally, Science 265 (1994) 1686.

[35] S.R. Langhoff, J. Phys. Chem. 100 (1996) 2819.

[36] C.W. Bauschlicher, Jr, S.R. Langhoff, Spectrochim. Acta A 53 (1997) 1225.

[37] D.J. Cook, R.J. Saykally, Astrophys. J. 493 (1998) 793.

[38] H. Piest, G. von Helden, G. Meijer, Astrophys. J. 520 (1999) L75.

[39] D.M. Hudgins, S.A. Sandford, L.J. Allamandola, J. Phys. Chem. 98 (1994) 4243.

[40] D.M. Hudgins, L.J. Allamandola, J. Phys. Chem. 99 (1995) 3033.

[41] D.M. Hudgins, L.J. Allamandola, J. Phys. Chem. 99 (1995) 8978.

[42] D.M. Hudgins, L.J. Allamandola, J. Phys. Chem. A 101 (1997) 3472.

[43] D.M. Hudgins, S.A. Sandford, J. Phys. Chem. A 102 (1998) 329.

[44] D.M. Hudgins, S.A. Sandford, J. Phys. Chem. A 102 (1998) 344.

[45] D.M. Hudgins, S.A. Sandford, J. Phys. Chem. A 102 (1998) 353.

[46] D.M. Hudgins, L.J. Allamandola, C.W. Bauschlicher, Jr, J. Fetzer, J. Phys. Chem. A 104 (2000) 3655.

[47] J. Szczepanski, M. Vala, D. Talbi, O. Parisel, Y. Ellinger, J. Chem. Phys. 98 (1993) 4494.

[48] J. Szczepanski, C. Chapo, M. Vala, Chem. Phys. Lett. 205 (1993) 434.

[49] J. Szczepanski, M. Vala, Astrophys. J. 414 (1993) 179.

[50] M. Vala, J. Szczepanski, F. Pauzat, O. Parisel, D. Talbi, Y. Ellinger, J. Phys. Chem. 98 (1994) 9187.

[51] J. Szczepanski, C. Wehlberg, M. Vala, Chem. Phys. Lett. 232 (1995) 221.

[52] J. Szczepanski, J. Drawdy, C. Wehlburg, M. Vala, Chem. Phys. Lett. 245 (1995) 539.

[53] C.W. Bauschlicher, S.R. Langhoff, S.A. Sandford, D.M. Hudgins, J. Phys. Chem. A 101 (1997) 2414.

[54] S.R. Langhoff, C.W. Bauschlicher, Jr, D.M. Hudgins, S.A. Sandford, L.J. Allamandola, J. Phys. Chem. A 102 (1998) 1632.
[55] C.W. Bauschlicher, Jr, D.M. Hudgins, L.J. Allamandola, Theor. Chem. Acc. 103 (1999) 154.

[56] D.M. Hudgins, L.J. Allamandola, Astrophys. J. 513 (1999) L69.

[57] R.E. Stratmann, G.E. Scuseria, M.J. Frisch, Chem. Phys. Lett. 257 (1996) 213.

[58] P.J. Stephens, F.J. Devlin, C.F. Chabalowski, M.J. Frisch, J. Phys. Chem. 98 (1994) 11623.

[59] A.D. Becke, J. Chem. Phys. 98 (1993) 5648.

[60] M.J. Frisch, J.A. Pople, J.S. Binkley, J. Chem. Phys. 80 (1984) 3265.

[61] M.J. Frisch, G.W. Trucks, H.B. Schlegel, G.E. Scuseria, M.A. Robb, J.R. Cheeseman, V.G. Zakrzewski, J.A. Montgomery, Jr., R.E. Stratmann, J.C. Burant, S. Dapprich, J.M. Millam, A.D. Daniels, K.N. Kudin, M.C. Strain, O. Farkas, J. Tomasi, V. Barone, M. Cossi, R. Cammi, B. Mennucci, C. Pomelli, C. Adamo, S. Clifford, J. Ochterski, G.A. Petersson, P.Y. Ayala, Q. Cui, K. Morokuma, D.K. Malick, A.D. Rabuck, K. Raghavachari, J.B. Foresman, J. Cioslowski, J.V. Ortiz, A.G. Baboul, B.B. Stefanov, G. Liu, A. Liashenko, P. Piskorz, I. Komaromi, R. Gomperts, R.L. Martin, D.J. Fox, T. Keith, M.A. Al-Laham, C.Y. Peng, A. Nanayakkara, C. Gonzalez, M. Challacombe, P.M.W. Gill, B. Johnson, W. Chen, M.W. Wong, J.L. Andres, C. Gonzalez, M. Head-Gordon, E.S. Replogle, J.A. Pople, GAUSSIAN 98, Revision A.7, Gaussian, Inc., Pittsburgh, PA, 1998.

[62] P. Weilmunster, A. Keller, K.-H. Homann, Comb. Flame 116 (1998) 62.

[63] M. Franklach, E.D. Feigelson, Astrophys. J. 341 (1989) 372.

[64] I. Cherchneff, J.R. Barker, A.G.G.M. Tielens, Astrophys. J. 401 (1992) 269.

[65] E. Peeters, S. Hony, C. Van Kerckhoven, A.G.G.M. Tielens, L.J. Allamandola, D.M. Hudgins, Astron. Astrophys. (in preparation).

[66] J.D. Bregman, in: L.J. Allamandola, A.G.G.M. Tielens (Eds.), Interstellar Dust, Kluwer, Dordrecht, 1989, p. 109.

[67] L.J. Bellamy, The Infrared Spectra of Complex Organic Molecules, Wiley, New York, 1958.

[68] D.M. Hudgins, L.J. Allamandola, Astrophys. J. 516 (1999) L41. 